\title{
Autorenfassung: Neufichteanismus in Rudolf Euckens Philosophie des Geisteslebens?
}

[erstveröffentlicht in: Fichte-Studien Band 35 (2010) (Wissen, Freiheit, Geschichte. Die Philosophie Fichtes im 19. und 20. Jahrhundert. Beiträge des sechsten internationalen Kongresses der JohannGottlieb-Fichte-Gesellschaft in Halle (Saale) vom 3. - 7. Oktober 2006)]

Hans Friedrich Fulda $2010 / 2014$ 
I. Rudolf Eucken in der Perspektive seiner Mit- und Nachwelt, insbesondere aber in der Sekundärliteratur

II. Ein kurzer Blick auf Euckens Vita

III. Die wichtigsten Schicksale und Bildungsfaktoren, die Euckens erste Lebenshälfte geprägt haben

IV. Grundsätzliche Differenzen zu Fichte

- a.: in methodischer Hinsicht

- b.: hinsichtlich erforderlicher Vororientierung

- c.: in inhaltlichen Hinsichten

- - : Welche Differenzen sich bereits am Titel von Euckens erstem Hauptwerk offenbaren

- - : Weshalb darin die zentralen Gedanken Fichtes keine Schlüsselbedeutung haben

V. Anschlussfragen

(1) Wie die Legende vom Neufichteaner Eucken zu erklären ist

(2) Welche Umstände die Entstehung und Verbreitung der Legende begünstigt haben

(3) Rückannäherung an Fichte in der Verbindungslinie ,Schleiermacher, Steffensen, Eucken“?

Literaturverzeichnis

\section{$\{\mid$ S. 107\}}

\section{$\boldsymbol{I}$}

Rudolf Eucken und Fichte, genauer: Fichte in Rudolf Eucken, — was für ein opakes Kapitel in der Philosophiehistorie des 19. und beginnenden 20. Jahrhunderts ist das! Je heller man es beleuchtet, umso intensiveres Dunkel strahlt davon aus. Nicht so sehr durch Euckens Mitwirken 1914-18 am »Krieg der Philosophen «, ${ }^{1}$ in den retrospektiv auch Johann Gottlieb Fichte wegen seiner Reden an die deutsche Nation hineingezogen wurde. Im Gegenteil, während dieser Phase unserer nationalen philosophischen Kultur oder vielmehr Unkultur nimmt sich Rudolf Eucken verglichen mit anderen nicht besonders unvorteilhaft aus. Fichtes Reden haben ihn weniger schlimm mit überheblichem Nationalismus infiziert als viele andere. Weder von Euckens Beiträgen zur Frage der deutschen Schuld am und im ersten Weltkrieg, noch von seinem Anteil an Schuldverleugnung soll daher hier die Rede sein. Erst recht nicht vom Übel, das Fichtes Nachleben mit dem Nationalsozialismus verbindet. ${ }^{2}$ Denn vor einem Absturz in diese Finsternis wurde Eucken, falls er dafür anfällig gewesen wäre, durch die Gnade eines früheren Todes bewahrt. Er ist 1926, hoch geachtet auch außerhalb Deutschlands, mit 8o Jahren gestorben. Nein, Eucken und Fichte bilden für uns ein dunkles Kapitel nur, weil zwischen beiden ein sehr undurchsichtiger Zusammenhang besteht. Von Anfang an wurde das Verhältnis Euckens zu Fichte merkwürdig undeutlich wahrgenommen, und auch in der Folge variiert die Wahrnehmung erheblich — wie Eucken überhaupt $\{\mid$ S. 108\} in der Meinung über seine Philosophie großen Schwankungen unterlag. Noch abgesehen von allen inhaltlichen Zuordnungsfragen sind bei ihm die Pendelausschläge — selbst die des bloßen Bekanntheitsgrades - ganz einzigartig.

Doch Rudolf Eucken war keine Sternschnuppe am Nachthimmel der Philosophie seiner Zeit. Nur allmählich ist er zu hohem Ansehen gelangt. Selbst sein erstes systematisch-philosophisches Hauptwerk und achtes Buch, das er 1888 mit 42 Jahren veröffentlichte, ${ }^{3}$ wurde ein »flop«; bis heute hat man's kaum gelesen. ${ }^{4}$

\footnotetext{
${ }^{1}$ Vgl. Hoeres, 2004.

${ }^{2} \mathrm{Vgl}$. Pesch, 1982.

${ }^{3}$ Eucken, Die Einheit des Geisteslebens, 1888. Als Vorbereitungsschrift darauf erschienen von Eucken im selben Verlag 1885 Prolegomena zu Forschungen über die Einheit des Geisteslebens in Bewußtsein und That der Menschheit.
} 
Andere Bücher Euckens hingegen, die von 1890 an in dichter Folge erschienen, erzielten hohe Verkaufszahlen, insbesondere nachdem ihr Verfasser 1908 den sieben Jahre zuvor gestifteten Nobelpreis für Literatur erhalten hatte - als erster Philosoph übrigens und einziger deutschsprachiger unter den bisher überhaupt nur vier damit gekrönten Fachgenossen. Das meistgelesene seiner Bücher ${ }^{5}$ erlebte, mehrfach neu überarbeitet, bis 1922 nicht weniger als 18 Auflagen.

Nach langen Jahren zurückhaltenden Interesses der Zunft und Leserschaft an ihm — sein erstes Buch war 1866 erschienen $^{6}$ — wurde Eucken also kurz nach der Jahrhundertwende ein erfolgreicher, hochgeachteter akademischer Lehrer und bald noch erfolgreicherer philosophischer Schriftsteller für gebildete Laien. Trotzdem erkannten ihn führende Köpfe nun und weiterhin als gleichrangig an. Edmund Husserl, z. B., schrieb 1916 zu seinem 70. Geburtstag einen Artikel, in dem er gleich eingangs konzedierte: zwei Wege seien möglich, »um das ursprüngliche, alle Erfahrungswelt in sich konstituierende Leben zu entdecken; zwei Wege, um zur wesentlichen Scheidung zwischen Menschen in der Natur und der Menschheit im Geiste durchzudringen, um die im Lebensgange der Menschheit sich aufsteigend bekundende Einheit des Geisteslebens zu erschauen und auf ursprüngliche Quellen zurückzuführen.« $\{\mid$ S. 109\} Den einen Weg habe Rudolf Eucken in seiner Philosophie des Geisteslebens betreten, den anderen die phänomenologische Philosophie. Diese müsse konsequenterweise bis zu den Höhen kommen, in denen sich Rudolf Euckens Philosophie bisher betätige. Schließlich aber müßten beide Philosophien »zu einer zusammenstimmenden Einheit verschmelzen «. ${ }^{7}$

Noch erstaunlicher als der allmähliche Aufstieg zu solcher Höhe des Ansehens ist Euckens jäher Absturz in die Vergessenheit bald nach dem Tod. Eine längere Darstellung von Lebensphilosophie der Gegenwart aus dem Jahr $1932^{8}$ verzeichnet Eucken nicht unter den Repräsentanten der Hauptrichtungen, obwohl eine der umfangreichsten systematisch-philosophischen Publikationen Euckens den Untertitel Eine Philosophie des Lebens trug. ${ }^{9}$ Dasselbe gilt vom Artikel Lebensphilosophie in Joachim Ritters Historisches Wörterbuch der Philosophie. ${ }^{10}$ Das auflagenstarke Handbuch Religion in Geschichte und Gegenwart (RGG), ${ }^{11}$ das über Eucken in seiner zweiten Auflage einen rühmenden Artikel enthalten hatte, lässt diesen Artikel nach dem zweiten Weltkrieg (vgl. die Auflage von 1958) ersatzlos entfallen. Wilhelm Totoks Handbuch der Geschichte der Philosophie $^{12}$ verzeichnet Eucken im Band zum 19. Jahrhundert nur noch als Autor eines Buchs über den deutschen Idealismus ${ }^{13}$ und im Band über das 20. Jahrhundert gar nicht mehr. So könnte man fortfahren. Wenn

\footnotetext{
${ }^{4}$ Das Exemplar des Werks im Heidelberger Philosophischen Seminar, z. B., war bis zu meiner Lektüre nicht vollständig aufgeschnitten. Paul Natorp allerdings, kein geringerer, hat das Buch eingehend gewürdigt. Beleg dafür ist seine Rezension (1892) in Philosophische Monatshefte, Bd. 28, S.154-185.

${ }^{5}$ Die Lebensanschauungen der großen Denker, 1890.

${ }^{6}$ De Aristotelis dicendi ratione, 1866.

${ }^{7}$ Zitiert nach: Die Tatwelt. Zeitschrift für Erneuerung des Geisteslebens. Jahrgang III, Heft 1/3. Jena 1927, S. 10.

${ }^{8}$ Erschienen in Philosophische Forschungsberichte. Heft 14. Berlin 1932. Autor war der Persönlichkeitspsychologe Philipp Lersch. (Die schwache Begründung der Ausgrenzung Euckens findet man auf S. 83 f.) Abgehandelt wurden neben Bergson, Dilthey, Simmel noch W. James, Ludwig Klages und Theodor Lessing.

${ }^{9}$ Eucken, Mensch und Welt, 1918, S.457 - Der späte Eucken hielt dieses Buch sogar für sein systematisches Hauptwerk (vgl. Eucken, Lebenserinnerungen, S.101).

${ }^{10}$ Ritter, 1980, Bd V, Sp. 135-140. Der Unterschlagung Euckens wird in diesem Artikel dadurch Vorschub geleistet, dass auch von der ethischen und christlichen Lebensphilosophie des frühen Schleiermacher nicht die Rede ist, obwohl deren Konzept durch seine Wirkung die romantischen und vorkritischen Auffassungen von Lebensphilosophie in Deutschland mit der Lebensphilosophie nicht nur von Eucken, sondern auch von Dilthey verbindet, also sich begriffsgeschichtlicher Betrachtung besonders empfehlen müsste (Siehe dazu unten V, 2.c.).

${ }^{11}$ RGG, 1930, Bd IV, S. 498 f.

${ }^{12}$ Frankfurt/Main, Bd. V 1986, VI 1990.

${ }^{13}$ Eucken, Die Träger des deutschen Idealismus. Leipzig ${ }^{1}$ 1915. Erwähnt wird die Auflage von 1924.
} 
gar diejenigen Kollegin- $\{\mid$ S. 110 $\}$ nen und Kollegen, die 30 bis 50 Jahre jünger sind als ich, nach ihrer Meinung über Rudolf Eucken gefragt werden, so ist die Antwort gewöhnlich ohne alle Ironie: Wer war Rudolf Eucken? Man stelle sich zum Vergleich die Reaktion auf eine entsprechende Frage nach Henri Bergson oder Bertrand Russell vor - zwei der anderen Nobelpreisträger unter den Philosophen, von denen der eine nur 13 Jahre jünger war als Eucken!

Noch rätselhafter wird die Sache, wenn es nicht bloß um den Bekanntheits- und Ansehensgrad geht, sondern um die Frage, als was für einer Rudolf Eucken unter den Philosophen seiner Zeit wahrgenommen wurde und was für eine Herkunft man seiner Philosophie zusprach. Damit kommt die Vagheit der Auskünfte über die Stellung ins Spiel, die Eucken zu Fichte einnimmt. Die 9. Auflage des »Ueberweg ${ }^{14}$ von 1902 (und ebenso die 10. von 1906) verbucht ihn (in § 26) noch unter »Einwirkungen Fichtes «. ${ }^{15}$ Gleich im Vorspann dazu werden »neue Erscheinungen« erwähnt, die »beweisen, wie Fichte wieder zu neuem Leben erwacht«. In den Ausführungen über Eucken, die sich außer auf dessen erstes systematisches Hauptwerk auch auf ein jüngeres Buch stützen, ${ }^{16}$ ist dann zwar von einer entschiedenen Neigung Euckens zum älteren Fichte die Rede, dunkel aber bleibt, woran die eigentlich evident werden soll. Ja, die Behauptung wird gleich wieder halb zurückgenommen, indem hinzugefügt wird, Eucken stehe auch Platon nicht fern. ${ }^{17}$ Das Ansichwahre und Ansichgute Platons werde nach Eucken zu einer lebendigen Wirklichkeit für uns nur in Verbindung mit der Selbsttätigkeit Fichtes — mehr als diese wolkige Aussage springt nicht heraus, obwohl doch das Insistieren auf Selbsttätigkeit der Vernunft Gemeingut der idealistischen Philosophie seit Kant war. Schon die Zusammenstellung all der Autoren, denen im »Ueberweg« eine Einwirkung Fichtes attestiert wird, lässt Zweifel aufkommen, ob mit dem $\S 26$ nicht bloß eine Restkategorie eingeführt wurde, ${ }^{18}$ weil unter jüngsten Strömungen der damaligen Philosophie eben auch ein Nachleben Fichtes $\{\mid$ S. 111$\}$ nicht fehlen sollte. ${ }^{19}$ Bereits 1906 ist aus dem Sammelsurium von Autoren mit angeblichen Einwirkungen Fichtes Max Stirner herausgenommen. Zehn Jahre später hat sich die Kategorie dieser Einwirkungen in Nichts aufgelöst. ${ }^{20}$ Eucken wird nun unter »Metaphysik der Geisteswelt« als deren Protagonist abgehandelt. Sieben Jahre später ist diese Rubrik schon wieder entfallen, und Eucken wird zum »Vorläufer einer neuen Metaphysik « gestempelt, ${ }^{21}$ nachdem Wilhelm Windelband 1907 von einer »idealistischen Metaphysik im Werden « gesprochen hatte, ${ }^{22}$ als deren Hauptvertreter Rudolf Eucken angesehen werden müsse. Dass in ihm Fichte weiterlebe, wird 1916 und 1923 im »Ueberweg« nicht mehr behauptet. Vielmehr wird Eucken nun generell zum »eigentlichen Führer der neuidealistischen Bewegung der Gegenwart «. Er sei aber nicht lediglich Denker, sondern »fast mehr noch Prophet und Reformator «. ${ }^{23}$

Verblüffender als all das ist die Genealogie, in die unser Mann nun, 1923, gestellt wird: er sei von Karl

\footnotetext{
${ }^{14}$ Ueberweg, ${ }^{9} 1902$, S. 252 f.

15 - neben Julius Bergmann, Friedrich Harms, Karl Fortlage, Max Stirner (!), Robert Schallwien, Heinrich Rickert und Hugo Münsterberg.

${ }^{16}$ Eucken, Der Kampf um einen geistigen Lebensinhalt.

${ }^{17}$ Schwer zu sagen, von welchem Gesichtswinkel aus da Fichte und Platon betrachtet werden, um in diese Konjunktion zu kommen!

18 - vor anschließend gesondert abgehandelten Einzelnen wie Lotze, Fechner, E.v. Hartmann, W. Wundt, Dilthey, Nietzsche.

19 - nach »Wiederaufleben Kants«, »Positivismus«, »Immanenzphilosophie«, »Empiriokritizismus«, aber noch vor dem Materialismus mit seinen Gegnern sowie dem Psychologismus.

${ }^{20}$ Vgl. die 11. Auflage von 1916, hrsg. v. K. Oesterreich, S. 457 ff.

${ }^{21}$ Vgl. die 12. Auflage des Ueberweg, 1923, S. 259 ff.

${ }^{22}$ Windelband, ${ }^{4} 1907$, S. 538.

${ }^{23}$ Ebd, S. 457 bzw. S. 560.
} 
Steffensen ausgegangen. ${ }^{24}$ Wer aber war der, und wodurch lässt sich seine geistige Vaterschaft an Rudolf Eucken belegen? Hierüber war uns im »Ueberweg « vor 1923 fast nichts gesagt worden.${ }^{25}$ So verwundert es nicht, dass in späteren Philosophiegeschichten, wenn von Rudolf Eucken überhaupt noch die Rede ist, über dessen intellektuelle Herkunft und Beziehung zu Fichte auch nichts Genaues, Beständiges mitgeteilt wird. ${ }^{26}$ Allerdings hat sich nach dem Zweiten Weltkrieg et- $\{\mid$ S. 112\} was von der alten Zuordnung Euckens zu Fichte erhalten. Doch die ist auch jetzt keine runde Sache. Noch im zuständigen Band der dritten Auflage der RGG von 1960 behauptet Hermann Lübbes Artikel über Neufichteanismus einerseits, den sachlichen Ausgangspunkt für eine Fichte-Erneuerung habe um 1900 vor allem Heinrich Rickerts Lehre geboten, dass sich die Wirklichkeit erst in einem praktischen Akt des Subjekts für dieses konstituiere, und im selben Kontext wird ausdrücklich Hugo Münsterbergs programmatischer Rückgang auf Fichtes Tathandlung erwähnt; andererseits aber wird dann doch auch die »kulturkritische Aufbruchs- und Tatmetaphysik « Euckens in den Neufichteanismus einbezogen, ${ }^{27}$ die dem Publikum bereits um 1888 vorlag. Neufichteanismus vor Verfügbarkeit seines sachlichen Ausgangspunkts? Ein jüngerer Autor hingegen, Kurt Wuchterl, ${ }^{28}$ erwähnt im Zusammenhang mit Schelers Denkweg einen angeblichen Neukantianismus Euckens, nachdem er diesen Eucken 14 Seiten vorher einen Fichteaner genannt hatte!

Was ist von so gespreizter Zuordnung zu halten? Fragen wir Max Scheler, der es eigentlich wissen musste, denn er hat bis zur Habilitation 1900 in Jena bei Eucken und Otto Liebmann studiert, bevor er zu den Bilderbuchphänomenologen nach München und dann zu Husserl ging. Scheler spricht von »starker Anknüpfung an Fichtes Tatidealismus bei Eucken. ${ }^{29}$ Aber er disqualifiziert dieses Urteil, indem er auch sagt, Eucken sei ausgegangen von Adolf Trendelenburg und eine zeitlang Schüler Lotzes gewesen. Denn ausgegangen war Eucken in Göttingen, wo er studierte, von Gustav Teichmüller, bei dem er in klassischer Philologie promovierte und von dem er erst nach dem Studium weiterempfohlen wurde an Trendelenburg. Schüler Lotzes aber war Eucken nach dem Zeugnis seiner Lebenser- $\left\{\mid\right.$ S. 113\} innerungen nie ${ }^{30}$ obwohl er in Göttingen studiert und dort frustriert Lotzes Vorlesungen gehört hatte. Was Scheler mit der Glaubwürdigkeit eigenen Erlebens an Eucken hervorhebt, ist denn auch etwas anderes: Eucken stehe an der Grenze zwischen wissenschaftlicher Philosophie und philosophischer Erbauungsliteratur. Er sei von gleichbedeutenden Kritikern sehr verschieden beurteilt worden. »Die einen sehen in der Verbindung von Prediger, Metaphysiker und Forscher, von homo religiosus und Denker, die Eucken darstellt, etwas besonders Wertvolles und weisen hin auf den reichen

\footnotetext{
${ }^{24}$ Ebd, S. 561.

${ }^{25}$ Die neunte und die zehnte Auflage (1902 und 1906) z B. verzeichnen nur das Geburts- sowie Todesjahr und berichten, Steffensen sei als »gefeierter Lehrer der Philosophie in Basel « gestorben. Die elfte Auflage (1916) verdirbt diese Information, indem sie den Namen »Steffensen« zu »Steffens« verkürzt. Erst die zwölfte Auflage (1923) macht über Steffensen und seine Philosophie nähere Angaben (S. 255 f.)

${ }^{26}$ Beispielsweise verzeichnet Frederick Coplestons A History of Philosophy Eucken - nach Fechner, Lotze, Wundt und dem 21 Jahre jüngeren Driesch, aber vor Trendelenburg und seiner »organischen « Weltanschauung - unter der Rubrik »The Revival of Metaphysics« (Vol. VII. London/New York 1963, S. 384 ff.). Er sei für seinen Aktivismus schon als Schüler von einem Schüler Krauses eingenommen worden. Doch welche belegbaren Spuren das hinterlassen hat und wie sie zu Euckens »activism« führen, wird verschwiegen. Was von Euckens Philosophie referiert wird, erinnert Copleston dann charakteristischerweise nicht mehr an Krause und auch nicht an Fichte, sondern an Hegel - mit dem einzigen Zusatz, die Probleme des Geisteslebens, mit denen sich der Weltanschauungsphilosoph Eucken abgibt, hätten seiner Botschaft zufolge keine begriffliche Lösung, sondern würden durch die Tat gelöst. Auch die Opposition von begrifflicher Lösung und Tat klingt nicht gerade nach Wiederbelebung eines Fichte'schen philosophischen Lehrstücks.

${ }^{27}$ RGG, Sp.1410. Ähnlich: Jahn, 2001, S.108.

${ }^{28}$ Wuchterl, 1995, S.178,192.

${ }^{29}$ Scheler, 1973, S. 261 ff; bes. 273 f.

${ }^{30} \mathrm{Vgl}$. Eucken, Lebenserinnerungen.
} 
intuitiven Gehalt seines Werkes; die anderen beklagen den Mangel an Anatomie in seinen Gedanken, die Unverbundenheit seiner Philosophie mit den Wissenschaften, die unmethodische Art seines Denkens und die große Unbestimmtheit und Vagheit des eigenartigen persönlichen Stils seiner Darstellung.« ${ }^{31}$

Nochmals also, zum letzten Mal: Wer war Rudolf Eucken; für welche Philosophie stand er und wie, insbesondere, verhält sich die zur derjenigen Fichtes? War er vielleicht gar kein »-ianer«, sondern Schönbergisch gesprochen »selber oaner«? Was kann man aus der Beschäftigung mit ihm und mit seinem Verhältnis zu Fichte heute über Fichte im 19. und 20. Jahrhundert lernen? - Werfen wir zur Beantwortung dieser Fragen angesichts der Vergessenheit so vieler Aspekte der Philosophie zwischen 1860 und 1920 zunächst einen flüchtigen Blick auf das äußere Leben und dann auf den Bildungsgang von Rudolf Eucken! Das wird uns auf Karl Steffensen zurückbringen und instand setzen, einige der jetzt schon auffällig gewordenen Züge an Euckens Denken zu verstehen, ohne dass es dazu der Annahme bedarf, Fichtes Philosophie sei darin auf neue Weise vorbildlich geworden.

\section{II}

Die wichtigsten Daten zum äußeren Leben sind schnell aneinandergereiht. Eucken war Ostfriese. $1846 \mathrm{im}$ ländlichen Aurich ${ }^{32}$ geboren und aufgewachsen beendete er dort bereits 1863 seine Schulzeit und bezog sogleich die Universität Göttingen. Nach einem gleichgewichtig der Philosophie \{|S. 114\} (insbesondere der Antike) und der klassischen Philologie gewidmeten Studium, vor allem bei Teichmüller, promovierte er 1866 mit einer Dissertation über den aristotelischen Gebrauch von Redeteilchen. ${ }^{33}$ Noch im selben Jahr wurde er von seinem Doktorvater an Trendelenburg weitervermittelt, der damals auf dem Höhepunkt seines Ansehens stand und den er bald zum Mentor gewann. In dieser Umgebung setzte er seine Aristoteles-Forschungen fort und übte gleichzeitig Gymnasiallehrer-Tätigkeiten aus, zunächst in Berlin, dann kurze Zeit in Husum und 1869 wieder in Berlin, wo er auch an der Fertigstellung von Bonitz‘ Aristoteles-Index beteiligt wurde. Wenig später, noch 1869, vertauschte er das Berliner Gymnasium mit einem in Frankfurt am Main. Dort ereilte ihn das Glück, dass Teichmüller, inzwischen in Basel, ihn 1871 als seinen Nachfolger auf eine Professur für Philosophie und Pädagogik vorschlug, weil er selbst nach Dorpat ging. In Konkurrenz mit Nietzsche, der von seiner Stelle in der klassischen Philologie auf eine in der Philosophie wechseln wollte, wurde Eucken, 25-jährig, nach Basel berufen, wo er dann nicht nur Kollege von Nietzsche war, sondern im eigenen Fach auch von Karl Steffensen. Doch schon nach kurzer Zeit, 1874, übernahm Eucken den von Kuno Fischer zugunsten Heidelbergs verlassenen Philosophie-Lehrstuhl in Jena. Dort heiratete er (1882) und hatte mit seiner Frau drei Kinder. Eines davon war Walter Eucken, der spätere Nationalökonom und Begründer des deutschen Ordoliberalismus sozialer Marktwirtschaft. $^{34}$

Die meisten der vielen Bücher, die Rudolf Eucken geschrieben hat, sind in Jena entstanden. Seiner dortigen Professur blieb er trotz mehrerer auswärtiger Rufe ${ }^{35}$ treu. Zusätzlich zur akademischen Anerkennung ${ }^{36}$

\footnotetext{
${ }^{31}$ Scheler, 1973.

32 — von Emden aus ungefähr ein Drittel der Wegstrecke nach Wilhelmshaven.

${ }^{33}$ Eucken, De Aristotelis dicendi ratione.

${ }^{34}$ Ein anderer Sohn, Arnold-Thomas, machte sich einen Namen in der physikalischen Chemie. Vgl. Gillispie, 1970, S. 413.

35 - u. a.1896 aus Freiburg, 1904 aus Tübingen auf die Nachfolge Sigwarts.

${ }^{36}$ Z. B. 1900 durch Einladung zur Festrede anlässlich der Jahrhundertfeier der Universität und im selben Jahr auch zu einer Goethe-Jubiläumsrede. Vgl. dazu Dathe, 2000a, S. 45-61.
} 
stellte sich bei ihm 1901 mit Erscheinen von Der Wahrheitsgehalt der Religion ${ }^{37}$ auch Autoren-Erfolg ein, der 1908 durch den Literatur-Nobelpreis kräftig $\left\{\mid\right.$ S. 115\} verstärkt wurde. ${ }^{38}$ Zusätzlich zum Wirken an der Universität und als philosophischer Autor entfaltete Eucken ausgedehnte Volksbildungsaktivitäten: Zur »Hebung« des Volksschullehrerstandes hielt er in Thüringen und bald auch außerhalb davon dutzende Vorträge. Während des Ersten Weltkriegs trat er mit unzähligen patriotischen Reden in Erscheinung; nach der Katastrophe aber versuchte er zu deren kulturkritischer Verarbeitung in publizistischen Schriften seinen Beitrag zu leisten. Übrigens war er unter den deutschen Philosophieprofessoren wohl der erste, der seine Botschaft auf zahlreichen Vortragsreisen persönlich ins Ausland trug: 1903 und 1914 nach Holland (Utrecht, Amsterdam, Leiden), 1908 (ohnehin) nach Schweden, 1911 nach England, 1920 in die USA, ferner nach Norwegen, Finnland, Ungarn und Bulgarien. Eine verabredete Vortragsreise nach China und Japan fiel lediglich dem Kriegsausbruch zum Opfer. Eines der letzten Bücher Euckens über Das Lebensproblem in China und in Europa (1922) war zusammen mit einem Chinesen (Carsun Chang) verfasst. 1920 zog sich Eucken aus dem aktiven Universitätsleben zurück. 1926, wie gesagt, ist er gestorben.

\section{III}

Um zu verstehen, was für eine Philosophie aus diesem Leben hervorging, und auszumachen, ob sich darin ein Neufichteanismus verbirgt, sollte man die prägenden Schicksale und Bildungsfaktoren der ersten Lebenshälfte ins Auge fassen. Grob gesprochen lassen sich sechs Entwicklungsphasen unterscheiden: zwei in Aurich, eine zunächst in Göttingen, dann in Berlin, Husum und Frankfurt, zwei in Basel und eine in Jena. Sie lassen sich verbinden durch jeweils neue Motive, die von der Phase ihres Aufkommens aus in mindestens eine spätere hinüberwirkten. \{|S. 116\}

(1) Am Anfang steht ein traumatisierendes Erlebnis: Mit fünfeinhalb Jahren verliert Eucken seinen Vater, der Postvorsteher in Aurich war und aus einer dort ansässigen, verarmten, früher aber wohlhabend gewesenen Bauernfamilie stammte; kurz danach verliert er auch seinen vierjährigen Bruder. So ist die Mutter, eine gebildete Pastorentochter, nun mit dem kleinen Rudolf allein und nimmt, weil die Witwenrente nicht zum Lebensunterhalt ausreicht, andere Kinder als Pensionsgäste ins Haus auf. Zwischen Mutter und Sohn entsteht eine innige Symbiose, die auch in die nächsten Lebensabschnitte hinein bestehen bleibt. Als Rudolf Eucken die Universität bezieht, muss der Haushalt in Aurich aufgegeben werden, um das Studium zu finanzieren. Die Mutter versorgt ihren Sohn am Studienort und macht seine weiteren Ortswechsel alle bis nach Basel mit ${ }^{39}$ Eucken lässt durchblicken, dass er darauf sein großes Harmoniebedürfnis zurückführt, aber auch die Fähigkeit, sich nüchtern gegen eine gleichgültige, wenn nicht feindselige, jedenfalls von scharfen Gegensätzen durchzogene Umwelt durchzusetzen. Dass er sich zu einem Genie der Verträglichkeit entwickelt hat, ist durch spätere Anekdoten ${ }^{40}$ ebenso bezeugt wie durch die ausgeprägte Tendenz seines Denkens, auf Versöhnung von Widerstreitendem

\footnotetext{
${ }^{37}$ Wieder mit Verlagsort Leipzig. Das Buch war sein elftes, dem dann noch 15 folgen sollten.

${ }^{38}$ Die Verleihung war übrigens an einen Wissenschaftler nach derjenigen an Mommsen im Jahr 1902 seit Stiftung des Literaturpreises (1901) bereits die zweite. Eucken verdankte sie der Tatsache, dass sich im Preiskomitee die Befürworter von Swinburne und die von Selma Lagerlöf gegenseitig blockiert hatten. Auf Eucken aber konnte sich eine große Mehrheit einigen, denn zu den Statuten des Preises gehörte nach dem Willen des Stifters die »Auszeichnung idealistischer Gesinnungen«.

${ }^{39}$ Vgl. die eindringliche Charakterisierung dieser Lebensverhältnisse, die wir Konrad Cramer verdanken: Rudolf Christoph Eucken - Nobelpreisträger für Literatur - Philosoph. In: Göttinger Jahrbuch, Band 44, 1996. Göttingen. S. 230-232.

${ }^{40}$ z.B. über Euckens persönliches Verhältnis zum Jenaer Antipoden Ernst Haeckel. Vgl. dazu Dathe, 2000b, S. 41.
} 
auszugehen. $^{41}$

(2) Von der Schulbildung wurde diese Tendenz nicht gebrochen, sondern eher verstärkt. Die Lehrer waren überwiegend protestantische Theologen; darunter vor allem, zuständig für die alten Sprachen, ein freigesinnter Lutheraner, mehr Theologe als Philologe, aber auch philosophisch gebildet. Er hatte sich gründlich mit Hegel und Krause beschäftigt und gewann großen Einfluss auf Euckens vielseitige Interessen. Eucken gibt uns in sei- $\{\mid$ S. 117\} nen Erinnerungen aber keinen Hinweis, dass er durch diesen Mann, den Rektor Wilhelm Reuter, für spezifische Ideen und Bestrebungen Krauses erwärmt worden sei, wie z. B. für die auf einen Menschheitsbund gehenden Aktivitäten der Krausianer. ${ }^{42}$

Durch seinen gymnasialen Mentor wie auch durch eigene Begabung war Eucken, obwohl erst 17, auf ein Studium an der Universität bestens vorbereitet. Er hätte von Vorkenntnissen her außer klassischer Philologie und Philosophie, wofür er sich entschied, ebensogut Theologie, Geschichte oder Mathematik studieren können. Nur sprach gegen die Theologie, dass - er mit dem zweiten Artikel des christlichen Glaubensbekenntnisses und mit der protestantischen Orthodoxie seine Schwierigkeiten hatte. Aus seiner Entscheidung gegen die profane Geschichte und - trotz großer Neigungen — gegen die Mathematik ist zu vermuten, dass er schon von der Schule her in die nach Hegels Tod virulent gewordene Orientierungs- und Identitätskrise philosophischer Weltanschauungen hineingezogen war. Schon damals, am Ende seiner Schulzeit, scheint ihm, dem besonders strebsamen Abiturienten, die Förderungswürdigkeit jugendlicher Ideale wichtig geworden und im Gegensatz dazu die verhängnisvolle Wirkung zum Bewusstsein gekommen zu sein, die es hat, wenn solche Ideale durch rigide Schulpraxis im Keim erstickt werden.

(3) Die Krise im Bildungssystem und in den modernen Weltanschauungen ging einher mit einem verstärkten Interesse für die antike Philosophie. Dieses Interesse hatten schon Schleiermacher und Hegel gefördert; nun aber sollte es zur Rettung aus der intellektuellen Lebensnot beitragen. Doch Lotze, der Philosoph in Göttingen, machte darauf keine Hoffnung — weder für Platon noch gar zugunsten von Aristoteles. Eucken konnte daher, wie er selbst gesteht, kein näheres Verhältnis zu Lotze gewinnen. Ebenso wenig konnte dieser ihm, dem gleichermaßen historisch und philosophisch Interessierten, plausibel machen, wie die Philosophie zu einem $\{\mid$ S. 118\} neuen, überzeugenden Konzept ihrer eigenen Möglichkeiten und Aufgaben gelangen solle und wie sie darin nicht nur den politischen und sozialen Umwälzungen Rechnung tragen könne, sondern auch dem Glaubwürdigkeitsverlust traditionaler religiöser Überzeugungen und Betätigungsweisen; all dies aber, während nun die historischen Kulturwissenschaften und die Philosophie auseinanderdrifteten — ebenso wie schon seit einiger Zeit die Philosophie und die Naturwissenschaften. So ist wohlverständlich, dass Eucken sich erst einmal einem gründlichen Aristoteles-Studium im Rahmen der klassischen Philologie hingab und sich nach seiner in Minimalzeit erreichten Promotion durch den Wechsel zu Trendelenburg noch enger an den Neuaristotelismus anschloss. Für eine philosophische Vorbildfunktion Fichtes war da, d. h. jedenfalls bis Ende der 60er Jahre, kein

\footnotetext{
${ }^{41}$ Exemplarisch dafür ist Die Einheit des Geisteslebens in Bewußtsein und That der Menschheit. Das Buch unternimmt den kühnen Versuch, durch den Entwurf eines »Lebenssystems der Personalwelt« (341 ff.) die der Wirklichkeit angemessenen Motive in den einander entgegengesetzten Weltanschauungs-»Syntagmen « des Naturalismus und des Intellektualismus verträglich zu machen. (S. u. unter IV c.) Überreinstimmend hiermit wird Eucken 1902 an seinem ehemaligen Lehrer Trendelenburg dessen »ausgleichende Denkart « würdigen. (Vgl. Eucken, Zur Erinnerung an Adolf Trendelenburg,S.120.)

${ }^{42}$ Auch ein Beitrag Euckens zum 100. Geburtstag K. Chr. Fr. Krauses deutet nichts dergleichen an. Obwohl es sich um eine Erinnerungsrede aus festlichem Anlass handelt, wird darin gesagt, dass die Verehrung des Redners nicht speziell Krause gilt, sondern der »gewaltigen Gesamtbewegung « der deutschen idealistischen Philosophie, zu der er gehörte. Am Ende spricht Eucken sogar unverholen aus, dass er sich »nicht in einer näheren prinzipiellen Übereinstimmung mit Krause « befindet (Eucken, Zur Erinnerung an K. Chr. Fr. Krause, S 41).
} 
Platz — schon deshalb, weil Fichte für diese Rolle historisch und philologisch zu ungebildet und in seiner Geschichtsphilosophie zu aprioristisch gewesen war.

Andererseits bestand für Eucken auch kein Anlass, sich in den Sog einer der neueren philosophischen Strömungen hineinziehen zu lassen, die gegen Ende der 6oer Jahre besondere Anziehungskraft hatten oder neu gewannen: Schopenhauers Pessimismus, der Rückgang auf Kant ${ }^{43}$ und E. v. Hartmanns Philosophie des Unbewußten. $^{44}$ Die begriffsgeschichtlichen Arbeiten Teichmüllers und Trendelenburgs neuaristotelischer Realismus befriedigten fürs erste sein Interesse. Sie eröffneten ihm einen Horizont für eigene Intentionen und empfahlen sich jedenfalls in handwerklicher Hinsicht — durch ihre Aufmerksamkeit auf die sprachliche Seite der Philosophie und durch die Verbindung philosophischer Denkweise mit dem Historischen. So verfasste Eucken auf dieser Stufe seiner Bildung außer seiner Dissertation fünf weitere selbständige Schriften teils zur Begriffsgeschichte, teils zu Aristoteles. (siehe S. 9 oben). Zu Trendelenburgs weitergehenden Bemühungen in der systematischen Philosophie allerdings und insbesondere zu ihrer naturrechtlichen Thematik verhielt er sich reserviert. Er bezweifelte, dass darin die Kantische Revolution der Denkungsart ihre volle Würdigung erfahren habe. ${ }^{45}$ Also dürfte er auch gewusst haben, dass sein Weg ihn von $\{\mid$ S. 119\} Trendelenburg entfernen werde, wenn er ein philosophisches Wort zu den andrängenden Problemen der kulturellen Modernisierung im letzten Drittel des 19. Jahrhunderts würde finden wollen.

Außenseiter war er noch in einer anderen Angelegenheit, die das patriotische Bewusstsein der Deutschen während der letzten Jahre vor der Reichsgründung betraf. Als Ostfriese, der 1868 auch in Husum tätig war, erlebte er von unten die Schattenseiten der Bismarckischen Brachialpolitik: zunächst an der aggressiven Zuspitzung der Schleswig-Holsteinischen Frage und der bürokratischen Art, in der die Folgen ihrer »Lösung « von Preußen aus durch schroffe Behandlung der einverleibten Regionen abgewickelt wurden. ${ }^{46}$ Aus dieser Perspektive verurteilte er dann auch Erscheinungen wie den Kulturkampf und die Durchsetzung des Sozialistengesetzes, wie überhaupt, auf die Reichsgründung zulaufend, den technisch-ökonomisch-politischen, nur noch den Tagesereignissen zugewandten »Realismus«, dem sich das »Volk der Dichter und Denker« nun hingab, ohne sich die Unwahrhaftigkeit im Beibehalten dieser Selbstzuschreibung einzugestehen. Nicht zuletzt missfiel ihm die geistige Trägheit, mit der die gebildete Schicht des Bürgertums all diese Veränderungen über sich ergehen ließ. In der Kritik hieran war Eucken mit Nietzsche schon eins, bevor er ihn kannte. Im Grunde war darin auch bereits angelegt, dass die von ihm vorerst nur erwogene Kulturphilosophie eine Philosophie der Tat und des Aufrufs zu kulturerneuerndem Wirken würde werden müssen. ${ }^{47}$ Fichtes als eines Lehrmeisters zu solcher Philosophie bedurfte es also nicht. Genau genommen taugte die Fichte'sche Philosophie angesichts der

\footnotetext{
${ }^{43}$ Liebmann, 1865.

${ }^{44}$ Hartmann, 1869 ff. (3 Bde.).

${ }^{45}$ Vgl. die Lebenserinnerungen. Zugunsten von Fichte hat Eucken die Vorbildfunktion, die Trendelenburg für ihn besaß, nie relativiert, wohl aber zugunsten stärkerer Vorliebe für Platon als für Aristoteles. (Ebd.) Nach dem Zeugnis der Lebenserinnerungen wurde sein letztes Aristoteles-Buch (Die Methode der aristotelischen Forschung in ihrem Zusammenhang mit den philosophischen Grundprinzipien des Aristoteles. Berlin 1872) von Lotze sogar als eine klare und übersichtliche Darlegung der Schäden gewürdigt, welche der aristotelischen Methode anhaften.

${ }^{46}$ Im Zuge solcher Abwicklung verlor z. B. Euckens oben erwähnter gymnasialer Mentor als unbeugsamer Althannoveraner sein Amt, weil er sich weigerte, nach dem Eid auf seinen hannover'schen Souverän nun einen Eid auf den preußischen König zu leisten.

${ }^{47}$ In der Perspektive ihrer Ausarbeitung geurteilt musste es zu einer »Philosophie der That « deshalb kommen, weil schon innerhalb der beiden zu überwindenden Syntagmen, des Naturalismus und des Intellektualismus, aus deren gegensätzlicher Zuspitzung die gesamte geistige Wirklichkeit »ein System der That, eine einzige Thatwirklichkeit [hatte] werden und damit einen engeren Zusammenhang, eine gewaltige Belebung [hatte] erhalten« müssen (vgl. Die Einheit des Geisteslebens, S. 330).
} 
inzwi- $\{\mid$ S. 120$\}$ schen gründlich veränderten Problemlage zu solchem Dienst auch gar nicht, und Eucken, der sich später in diesem Sinne äußerte, dürfte sich dessen schon damals bewusst gewesen sein. Allenfalls konnte an Persönlichkeit und Charakterstärke, wie Fichte sie besessen hatte, beim Publikum appelliert, und sein prophetischer Eifer, sein Predigerpathos konnte bewundert werden. Aber diese Züge hatte schon Trendelenburg 1862 an Fichte gerühmt ${ }^{48}$, ohne deshalb jemals als Fichteaner zu erscheinen. ${ }^{49}$

(4) Nicht programmatisch zurückgreifend auf Fichte, aber mit Nietzsches gleichzeitiger Basler Wirkung konform, mochte die vorerst nur vage anvisierte Kulturphilosophie Euckens darauf ausgehen, in einer neu zu entwickelnden rhetorischen Ausdrucksweise exoterisch aufzutreten und damit wie Nietzsche eine breitere Öffentlichkeit als die der Hörsääle anzusprechen. Auch diese Tendenz hat sich nicht nur bei Eucken, sondern hatte sich längst in der Identitätskrise der Philosophie nach Hegel — als Zug zur Weltanschauungsphilosophie — angebahnt. ${ }^{50}$ In der Basler akademischen Nähe zu Nietzsche aber musste Eucken zu einem Schopenhauer entgegentretenden Tatpathos neigen und zur Bekämpfung des Pessimismus seinen Beitrag leisten wollen gerade auch dann, wenn er, wie ausdrücklich versichert ${ }^{51}$ Nietzsches allzu subjektives philosophisches Künstlertum vermeiden und mit dem eigenen Projekt im akademischen Bereich verbleiben wollte. Allerdings verlangte das eine bedächtigere philosophische Entwicklung, als Nietzsche sie durchlief: Erst im letzten Jahr, bevor dieser verstummt, wird Eucken das lange vorbereitete systematisch-philosophische Werk vorlegen. ${ }^{52} \mathrm{Er}$ bleibt mit ihm noch ganz im Rahmen der Zunft und würde allein damit ${ }^{53}$ vermutlich von keinem als ein »Neufichteaner« $\{\mid$ S. 121\} wahrgenommen, obwohl in ihm alle wichtigen Motive des genuin Eucken'schen Denkens versammelt sind.

$\mathrm{Zu}$ Beginn seines Auftretens in Basel hingegen war Eucken noch ein ganzes Stück davon entfernt, Nietzsche mit eigenen unzeitgemäßen Betrachtungen zur Seite treten zu können. In seiner akademischen Lehre wollte er die Trendelenburgische Orientierung am aristotelischen Realismus und Entelechiebegriff durch eine Annäherung an die platonische Auffassung von Philosophie ersetzen und in einer nachsystematischen Form (also gewiss nicht sich Fichte als Philosophen zum Vorbild nehmend) »analytisch« die metaphysischen Voraussetzungen von Ethik aufklären, um damit die Frage zu beantworten, welche Fassungen von Metaphysik mit einer für die eigene Gegenwart verbindlichen Ethik vereinbar sind und welche nicht. Daneben, aber vorläufig ohne den Anspruch wissenschaftlicher Begründung, wollte er in Vorlesungen Hauptfragen der gegenwärtigen Philosophie erörtern. Man beachte, dass beides zusammen — anfangs der 70er Jahre - eine Arbeit war, in der er nicht nur mit dem zwei Jahre älteren Nietzsche konkurrierte, sondern sich auch gegen den nur ein paar Jahre älteren von Hartmann abgrenzte sowie von den ungefähr gleichaltrigen Begründern des Neukantianismus unterschied. Sie alle gehörten einer Alterskohorte an: Eduard von Hartmann war 1842 geboren worden, Hermann Cohen ebenfalls, Alois Riehl sowie Nietzsche 1844 und Wilhelm Windelband 1848. Von Anbeginn also befand Eucken sich in wetteifernder Distanz zu deren Bestrebungen. Eduard von Hartmann, z.B., war ihm (wie auch für Nietzsche) noch zu stark von Schopenhauer infiziert. Die den Rückgang auf Kant

\footnotetext{
${ }^{48} \mathrm{Vgl}$. Adolf Trendelenburg, 1862, insbes. S. 31ff.

${ }^{49}$ Auch Nietzsche nahm keine Affinität zu Fichte an Eucken wahr, als dieser sich gegen ihn in der Konkurrenz um die Basler Philosophieprofessur durchsetzte. Ihm erschien er als »junger talentvoller Aristoteliker [...], mit der Fackel Trendelenburgs in der Hand « (Nietzsche, 1986, S.192).

${ }^{50}$ Man vergesse nicht, dass »Philosophie der Tat« als ein linkshegelianisches Programmwort aufgekommen war! (Vgl. Stuke, 1963.)

${ }^{51}$ Vgl. Eucken, Lebenserinnerungen, S. 77.

${ }^{52}$ Eucken, Die Einheit des Geisteslebens in Bewußtsein und That der Menschheit.

53 — d. h. für sich und ohne die vom Titel geweckten Assoziationen.
} 
propagierenden Tendenzen hingegen erschienen ihm bald als Versuche, lebendige Bestrebungen der Gegenwart zu unterdrücken. Oder um es mit seinen eigenen, später veröffentlichten Worten zu sagen: »Das Zurück zu Kant hat [...] ein Recht, sofern es die Aufforderung enthält, in Kant die Höhe der weltgeschichtlichen Arbeit zu erklimmen, die in ihm begonnene Umwälzung anzuerkennen und nach besten Kräften weiterzuführen. Werden wir aber geheißen, das ganze Gerüst des Kantischen Systems [...] festzuhalten, dem überreichen 19. Jahrhundert allen eigenen Ertrag für den inneren Aufbau des Geisteslebens abzusprechen und unsere in mächtigster Bewegung und Gärung befindliche Zeit an die Formeln der Vergangenheit zu binden, [...1, so sagen wir $\{\mid \mathrm{S}$. 122\} Nein und abermals Nein und fordern gegenüber einem solchen Zurück zu Kant ein Los von Kant, ein Hinaus über Kant. ${ }^{54}$

Der Kontext, in dem das gesagt ist, lässt keinen Zweifel, dass die Forderung auch besagen soll: hinaus über Fichte, Schelling, Hegel, Schleiermacher; hinaus über das Lebens- und Bildungsideal des deutschen Neuhumanismus von Goethe, Schiller, Humboldt; hinaus über Schopenhauer und den Positivismus! Aber die Aufgabe, dieses »Hinaus über ...« in einWerk systematischer Philosophie zu verwandeln, betrachtete er vorläufig, d. h. in den frühen 70er Jahren, nicht als sein eigen Ding.

(5) Da trafen ihn erneut zwei Schicksalsschläge in einem Jahr: 1872 starb unerwartet Trendelenburg, in dem er einen väterlichen Freund verlor, und starb an Krebs seine Mutter, die ihm ein alter ego gewesen war. Das brachte ihn nach eigenem Bekunden »aus dem Gleichgewicht ${ }^{55}$ Er fragte sich, ob er nicht den Beruf eines akademischen Lehrers der Philosophie aufgeben und sich mit ganzer Kraft sozialen Problemen sowie dem Sozialismus zuwenden solle. Die Lebenskrise war also unterschwellig auch eine Krise seiner bislang eher bescheidenen eigenen philosophischen Zielsetzung und der mit ihr bis dahin ziemlich locker verbundenen Wahrnehmung der moralischen und kulturellen Brüche im europäischen Geistesleben der eigenen Gegenwart, die nun ins letzte Drittel des 19. Jahrhunderts eingetreten war.

In dieser mentalitätsgeschichtlichen Lage, persönlichen Verfassung und philosophischen Grenzsituation, in der Eucken sich 1872 oder kurz danach befand, scheint tatsächlich Karl Christian Friedrich Steffensen, der eine Generation ältere Kollege, eine wichtige Rolle für ihn bekommen zu haben. 1816 in Flensburg geboren, ${ }^{56}$ war auch er — nicht anders übrigens als der $\{\mid$ S. 123\} Eutiner Trendelenburg — ein »Nordlicht«. Doch hatte er sich Philosophie nicht geradewegs durch zünftiges Universitätsfachstudium angeeignet, sondern anfangs Jura und Geschichte studiert (zunächst in Kiel, dann in Berlin bei von Savigny und Ranke, dann wieder in Kiel und nun mit der Absicht, über Rechtsphilosophie im Mittelalter zu promovieren). Krankheitshalber hatte er aber sein Studium unterbrechen müssen und sich zur Wiederherstellung seiner Gesundheit mehrere Jahre in Südfrankreich und Italien aufgehalten, wo er sich vorwiegend mit Philosophie beschäftigte. Nach der Rückkehr und einem einjährigen Wirken als Hauslehrer hatte er 1841 in Kiel promoviert und sogleich seine Hofmeistertätigkeit fortgesetzt: zunächst als Betreuer zweier schweizer Bankiers-Söhne beim Studium in Paris, dann als »Gouverneur« der beiden Söhne Christian Augusts, des Herzogs von Schleswig-Holstein-SonderburgAugustenburg, dem er später auch als Privatsekretär und Agent in diplomatischen Missionen diente. 1852

\footnotetext{
${ }^{54}$ Eucken, Lebensanschauungen, S. 418 f. In der ersten Auflage von 1890 finden sich diese Sätze noch nicht. Aber auch dort wird (S. 460 ff.) schon der Überzeugung Ausdruck gegeben, dass weder bei Kant noch bei der nachkantisch-idealistischen Systemphilosophie oder bei Schopenhauer, noch beim Naturalismus des späteren 19. Jahrhunderts Halt zu machen oder zu finden ist.

${ }^{55}$ Eucken, Lebenserinnerungen

${ }^{56}$ Vgl. zum Folgenden den Artikel über Steffensen in der Allgemeinen deutschen Biographie. Band 54, S. 451 ff., sowie den entsprechenden Artikel in Schleswig-Holsteinisches Biographisches Lexikon, hrsg. v. O. Klose und E. Rudolph. Neumünster 1974. S.254-258.
} 
habilitierte er sich in Kiel für Philosophie und las dort, wenn er nicht krank war, mit großem Beifall. Von seinen philosophischen Überzeugungen war Heinrich Gelzer, ${ }^{57}$ der mit ihm seit gemeinsamen Zeiten in Rom und Paris befreundete Basler Historiker, Diplomat und (ab 1852) Herausgeber der Protestantischen Monatsblätter für innere Zeitgeschichte, so beeindruckt, dass er 1854 seine Berufung auf eine Professur für Philosophie an der Universität Basel erwirkte, die Steffensen mit viel Lehrerfolg — 1864 als rector magnificus — bis zu seiner frühen Emeritierung im Jahr 1879 wahrnahm. ${ }^{58}$ In Basel ist er auch, 1888, gestorben.

Ähnlich wie Christian Hermann Weiße, der Lehrer Lotzes, und Fichtes Sohn Immanuel Hermann vertrat Steffensen einen protestantisch-christlichen spekulativen Theismus. Gleich dem jüngeren Fichte wollte er die Philosophie nicht mehr in reflexionsphilosophischer oder dialektischer Manier fortsetzen, sondern auf die Erfahrung gründen. Doch im Unterschied zu ihm versuchte er nicht, auf dieser Basis die alten, bereits von idealistischen Systemphilosophen umgeformten Disziplinen, wie insbesondere die Metaphysik, die Psychologie, Anthropologie und Ethik, in neuer Weise systematisch auszuführen. Anders als Weiße war er auch $\{\mid$ S. 124\} nicht sehr an christlicher Dogmatik interessiert, sondern vor allem — irritiert durch den sich ausbreitenden Historismus — an unaufgehellten, stillschweigend christlichen Voraussetzungen weltgeschichtlicher Betrachtung großer historischer Zusammenhänge. Seine Überzeugung war, dass derartige Betrachtungen nur zusammen mit dem Explizitmachen und Rechtfertigen solcher Voraussetzungen fruchtbar sein und Einsicht ins eigene Leben verschaffen können. Dazu hatte er sich, außer von Schleiermacher, philosophisch vor allem von Kants Religionsschrift anregen lassen. Ihre Lehre von der religiösen Wiedergeburt zu einem sittlichen Charakter projizierte Steffensen — auch unterm Eindruck von Religionsphilosophie des späten Schelling — auf den großen Maßstab der Weltgeschichte, in deren Strom sich der sittliche Charakter eines bedeutenden Menschen bildet. Von hier aus glaubte er sich berechtigt anzunehmen, dass in der Geschichte ideale Mächte als Kundgebungen Gottes wirken. Das Respektieren ihres Wirkens sollte ermöglichen, die subjektive Gefühlsfrömmigkeit (nach Art der Glaubenslehre Schleiermachers) stärker durch objektiven Gehalt religiöser Überzeugung zu befestigen, als Schleiermacher es vermocht hatte. Im Einzelnen aber sollte die Annahme jener Mächte empirisch zu bestätigen oder zu widerlegen sein.

Zugleich stand Steffensen damit, wie zweifellos auch Eucken, in Gegensatz zum Comte'schen Positivismus, wenn auch nicht zu allem Naturalismus. ${ }^{59}$ Allerdings hatte er, überwiegend auf die akademische Lehrtätigkeit konzentriert, außer Gelegenheitsaufsätzen in den Protestantischen Monatsblättern nichts veröffentlicht. Aber Eucken, der sich in seinen letzten Basler Jahren intensiv mit den spätantiken Kirchenvätern beschäftigte, dürfte diese Arbeiten gekannt und eine sehr hohe Wertschätzung für ihren Verfasser erlangt haben. Er hat später (1890) zur postumen Sammlung und Neuedition der Aufsätze ein langes Vorwort geschrieben, ${ }^{60}$ wie auch ein kürzeres zur Veröffentlichung eines nachgelassenen, Fragment geblie- $\{\mid$ S. 125\} benen

\footnotetext{
${ }^{57}$ Vgl. Ueberweg 1926, S. 255, und den Artikel über Heinrich Gelzer in der Allgemeinen Deutschen Biographie. München 1907 (Nachdruck Berlin 1971). Band 49. S.277-284.

58 - übrigens seit 1859 durch Heirat von Maria Magdalena Burckhardt familiär verbunden mit dem Kulturhistoriker Jakob Burckhardt.

${ }^{59}$ Vgl. Karl Steffensen. Gesammelte Vorträge und Aufsätze mit einigen Erinnerungsblättern von Freunden und Schülern, 1890. S. 374-378.

${ }^{60}$ Karl Steffensen, Gesammelte Aufsätze. (Angereichert durch »Erinnerungsblätter von Freunden und Schülern« und mit einem Geleitwort Heinrich Gelzers versehen, das durch dazwischen getretenen Tod fragmentarisch blieb, erschienen die Aufsätze am selben Ort und im selben Jahr auch unter dem zuvor angegebenen Titel ohne den Namen eines Herausgebers, als der vielleicht Gelzer vorgesehen gewesen war.)
} 
umfangreichen Steffensen'schen Werkes über Philosophie der Geschichte. ${ }^{61}$ Die Vorworte machen wahrscheinlich, dass Eucken knapp 20 Jahre früher zur Bewältigung seiner intellektuellen Krise gewichtige Anregungen von Steffensen empfangen hatte. An dessen Gedanken rühmt das erste Vorwort gleich zu Beginn den »Zug ins Große und Kosmische« — dass darin »die Schicksale des Geisteslebens ... den Kern des Weltgeschehens « bilden und die menschliche Erkenntnis nicht »in matter Reflexion « vor den Dingen stehen bleibt, sondern »durch Eindringen in die Tiefen der Geisteswelt sich einer vollen und ganzen Wahrheit« zu bemächtigen suche: »das Denken auf die Höhe weltumfassender Tatsachen zu führen und zugleich diese Tatsachen zur vollen Wirkung für das Menschheitsleben zu bringen — das ward der Angelpunkt der Aufgabe. Von diesem Centrum aus sollte der ganze Umkreis des Wissens und Seins in eine erhöhende Umwandlung hineingezogen werden.«(Steffensen, 1890, S. XXX)

Das Zitierte klingt, als habe Eucken darin Niederschriften der eigenen, seinerzeit von Steffensen bezogenen Anstöße verwertet; und er konnte dem auch, auf sich selbst wie auf Steffensen bezogen, hinzufügen, dass nun aber (im Unterschied zu den älteren Bestrebungen der spekulativen Philosophie von Fichte bis zu Hegel) der Intellekt innerhalb des Geisteslebens keine bevorzugte Stellung beanspruche und die Erfahrung davor bewahrt werde, sich den Forderungen des Denkens beugen zu müssen. ${ }^{62}$ Die Erfahrung — sowohl der Natur als auch des geschichtlichen Lebens - gelange zu unbefangener Anerkennung, und doch gehe das Streben auf einen Zentralbegriff. - Man könnte aus Euckens Vorworten zu Steffensen, um die gemeinsamen Bestrebungen beider zu charakterisieren, noch seitenlang zitieren. Ich hoffe, das Angeführte macht für sich schon plausibel, dass man es hier mit dem Keim der zweiten, anspruchsvolleren Eucken'schen Idee von Philosophie zu tun hat. Auf jeden Fall zeigt es, dass darin von einem direkten, programmatischen Rückgriff auf Fichte nicht die Rede sein $\{\mid$ S. 126\} kann, noch gar von Anschluss an ein »Zurück zu Fichte«, das andere damals praktizierten oder kurz davor propagiert hatten.

Zusätzlich zu den schon genannten Motiven gab Steffensen Eucken mindestens zwei weitere Impulse, die aus seiner respektvollen Auseinandersetzung mit Schleiermacher hervorgegangen waren, aber auch gegen Ansteckung durch Fichtes Spätphilosophie immunisierten: 1. Die Idee einer überpersönlichen Vernunft darf nicht an die Stelle persönlicher Freiheit treten, die unbedingte Forderungen enthält. Wir sind berechtigt und in unserer Erkenntnisarbeit genötigt, auch wenn diese dadurch prima vista behindert wird, Begriffe heranzuziehen, die der Sphäre der individuellen Persönlichkeit und ihres Urteilens zugehören, wie z. B. die Begriffe individueller Freiheit, Kunst, Tat, des Guten und Bösen, das getan wird oder uns widerfährt. Andernfalls hätten wir auch keinen Maßstab, unsere wirkliche Welt und die Geschichte, aus der sie hervorgegangen ist, wahrhaft zu beurteilen. - 2. Wie schon bei Schleiermacher liefert dabei der Gedanke des Lebens den eigentlichen Zentralbegriff: den eines persönlichen Kerns eines jeden, einer reinen Innerlichkeit, die den ganzen Menschen in seinen »Wesensverhältnissen« als tätige Kraft gegenüber höheren geistigen Ordnungen durch »Wesenserfahrungen« zur Erschließung kommen lässt. Aber dieser Zentralbegriff muss schärfer und anders als bei Schleiermacher gefasst werden: freilich nicht so empiristisch, dass uns kein Idealbewusstsein mehr zur Erkenntnis Gottes und einer vollkommenen Welt hindrängen will; aber auch nicht so idealistisch, dass sich bei

\footnotetext{
${ }^{61}$ Zur Philosophie der Geschichte von Karl Steffensen. Auszüge aus seinem handschriftlichen Nachlaß. Mit einem Vorwort von Prof. R. Eucken. Basel 1894. Diese und die beiden zuvor genannten Publikationen darf man als Quelle für Ueberwegs Behauptung vermuten, Eucken sei von Karl Steffensen ausgegangen.

${ }^{62}$ In seiner Kurzbiographie Gustav Teichmüllers (Allgemeine Deutsche Biographie, Bd. 37, ${ }^{1} 1894$ ) hat Eucken dann auch an dessen späten religionsphilosophischen Bemühungen besonders hervorgehoben, dass sie den »eingewurzelten Intellektualismus« überwinden wollten.
} 
uns keine Angst mehr regt und keine Klage erhebt angesichts der Welt in ihrer dunklen Rätselhaftigkeit und angesichts der darin miteinander einen unentschiedenen Kampf führenden guten und bösen Mächte.

Mit all dem und mit seiner prophetenhaften Ausstrahlung, die ihm nachgesagt wird, ist Steffensen gewiss nicht zu einem späten Lehrer Euckens geworden. Er hatte ja selbst keine ausgebildete systematische Philosophie. Vielleicht wurde er für sein weiteres Geschichtsdenken sogar seinerseits von Gesprächen mit Eucken stimuliert. ${ }^{63}$ Aller Wahrscheinlichkeit nach aber war er für diesen zwischen 1872 und 1874 Anreger und Ermutiger zu einem anspruchsvolleren Philosophiekonzept. $\{\mid$ S. 127 $\}$

(6) Natürlich war das Konzept noch nicht das systematisch-philosophische Werk, das aus ihm nun hervorgehen sollte. Die Arbeit, es zu schaffen, hat noch fast 15 Jahre in Anspruch genommen. Sie ist also erst fertig geworden, nachdem Eucken die Lebensmitte überschritten hatte. Wie und als was das Werk zustande kam, muß hier nicht mehr weit verfolgt werden. Denn auch für es, d. h. für Die Einheit des Geisteslebens in Bewußtsein und That der Menschheit, gilt: Fichte ist darin nicht zu neuen Ehren gekommen — trotz der emphatischen Rede von »Tatleben « und »Tatgeschehen «, ${ }^{64}$ trotz der Zusammenstellung »Bewußtsein und Tat «, der Ausrichtung auf »Einheit des Geisteslebens« und der betonten Forderung geistiger Selbsttätigkeit. Denn nicht ein direkter Rückverweis auf Fichte, sondern nur der Kontext, in welchem Steffensen für Eucken wichtig geworden ist, informiert uns über die Motive zu diesen Akzenten im späteren Werk. Erst von hier aus erklärt sich auch die Art und Weise, wie Eucken Fichte — oder was er von ihm bis dahin rezipiert hatte — in sein weiteres philosophisches Denken integrierte und warum es zu dieser Verarbeitung keines erneuten, intensivierten Fichte-Studiums bedurfte, sondern im Gegenteil ein solches Studium Eucken sogar bei der Verwirklichung seiner weltanschauungsphilosophischen und kulturkritischen Intentionen hinderlich gewesen wäre.

Bereits Euckens »Forschungen ${ }^{65}$ hierzu verfolgten ein Philosophie-Programm, das sich in grundsätzlicher Differenz mit Fichte befand und ein Bekenntnis zu Fichteanischer Reorientierung der Philosophie a limine ausschloss. Denn schon die zu bearbeitenden Probleme ergeben sich, und ihre Bearbeitung hat sich zu rechtfertigen aus einer Zeitlage, die — anders als diejenige Fichtes — es ausschließt, Zuflucht zu suchen »in dem seelischen Inneren des Einzelnen als einem der Verwirrung und Entzweiung unzugänglichen Grunde «. ${ }^{66}$ Nach Analyse der Zeitlage nämlich sind »die letzten Tiefen, die Grundformen des Lebens selbst vom Streit ergriffen und in die Ungewißheit hineingezogen ${ }^{67}$ Es geht also nicht mehr an, die Schicksale des Geisteslebens, die den Kern des Weltgeschehens bilden in denkender Reflexion zu ergrübeln oder aprioristisch zu konstruieren und bei solchem Rückgang meines philosophischen Bewusstseins in dessen ei- $\{\mid$ S. 128\} genes Innerstes, das sich von demjenigen anderer angeblich nicht mehr unterscheidet, bereits für die Aufdeckung seines inneren Handelns den Anspruch einer pragmatischen Geschichte des menschlichen Geistes zu erheben. ${ }^{68}$ Vielmehr bedarf es zur Ausführung des Konzepts nun umfangreicher empirischer Forschungen auf dem Gebiet der historischen Geisteswissenschaften. Diese Forschungen aber dürfen die aktuelle Zeitlage mit ihren

\footnotetext{
${ }^{63}$ Die 1894 postum veröffentlichten Fragmente zu dem von Steffensen geplanten Werk über Philosophie der Geschichte stammen erst aus den Jahren 1874-81.

${ }^{64}$ Charakteristischerweise aber fällt fast nie der Fichte'sche Ausdruck »Tathandlung «.

${ }^{65}$ Vgl. den Titel des das Werk von 1888 ankündigenden Buches: Prolegomena zu Forschungen über die Einheit des Geisteslebens in Bewußtsein und That der Menschheit.

${ }^{66}$ Eucken, Prolegomena, S.19.

${ }^{67}$ Ebd.

${ }^{68}$ Vgl. dagegen Fichte, Über den Begriff der Wissenschaftslehre, § 7.
} 
spezifischen Problemen nicht nur als abstrakten Bereich nehmen, der vom gesellschaftlichen und außerphilosophischen kulturellen Leben abgehoben ist. Sie müssen sich die spezifisch philosophischen Probleme in der Perspektive aufs Arbeitsleben der modernen industriellen und professionalisierten Gesellschaft erschließen. Dabei ist zu beachten, dass in solchem Leben »die Gesamtheit des Handelns von Gegensätzen durchzogen« ist, dass »Bedingungen, Richtungen und Ergebnisse« in ihm »ein ungelöstes Durch- und Gegeneinander « zeigen. ${ }^{69}$ Das eigentliche Problem aber besteht noch nicht darin. Es ist auch ungenau identifiziert mit der Feststellung, dass der modernen Kulturbewegung in der Entwicklung solcher Gegensätze ein »fortwährender Protest des unbefriedeten Menschheitslebens« widersteht, weil sich die Menschen dagegen sträuben, »bloßes Werkzeug zu werden«. Die Weigerung, »das Rad eines willen- und vernunftlosen Weltprozesses vernichtend über sich hinrollen zu lassen«, mag einander entgegengesetzte Ausdrucksformen annehmen: die optimistische und aktionistische, im Namen der Freiheit — oder des Glücks aller — dem vorliegenden Kulturleben den Krieg zu erklären; oder die pessimistische, den Willen oder »die Welt zu verneinen und das Nichtsein dem Sein vorzuziehen ${ }^{70}{ }^{70}$ Unverwechselbar wird das Problem erst durch Berücksichtigung eines weiteren Gesichtspunkts. Die Menschheit scheint sich »zu geschlossener Arbeit nicht einen zu können, ohne dem zu entsagen, worauf das Verlangen eines jeden besteht: Wert und Selbstleben der Persönlichkeit. Die Gegensätze persönlichen und unpersönlichen Lebens bleiben demnach unverglichen wider einander stehen. Ihr aufs tiefste in die Beweggründe und Gefühle eingreifender Zusammenstoß erklärt zum guten Teil die Rastlosigkeit der Neuzeit, jenen eigentümlichen revolutionären Zug, der ihr selten ruhiges Schaffen und noch seltener ein reines Erfreuen an $\{\mid$ S. 129\} demselben gestattet, der jedem Erfolge einen heimlichen Gegner zugesellt. $\ll^{71}$

Das Problem besteht also nicht darin, aus der Kantischen Revolution der Denkungsart in Sachen Metaphysik eine Wissenschaftslehre $\mathrm{zu}$ machen und diese $\mathrm{zu}$ einem System aller philosophischen Wissenschaften, das sie und sich selbst zurück in den Ausgangspunkt führt. Es ist vielmehr eines der modernen Gesellschaft, das im nachkantischen deutschen Idealismus allenfalls von Hegel wahrgenommen wurde, in seiner vollen Schärfe aber erst durch neue, nachhegelische Polarisierungen ins Bewusstsein trat. Was das für Euckens Verhältnis zu Fichte mit sich brachte, ist nun näher zu betrachten.

IV

Zusätzlich zur Bearbeitung des systematischen Problems, die aufs Werk von 1888 zulief, gehörte zur Ausführung des Programms ein weiteres, zwei Jahre später fertig gewordenes, historisches Buch. ${ }^{72}$ Auch mit dem so verstärkten Zusammenhang von erster und zweiter Lebenshälfte bleibt Eucken von Fichtes Philosophie weit entfernt. Grundsätzliche Differenzen bestehen in mindestens drei entscheidenden Hinsichten. Man kann sie schon der Programmschrift von 1885 entnehmen, findet sie in den nachfolgenden Werken aufrecht erhalten und erfasst das ganze Programm erst voll, wenn man das Ergänzungsverhältnis berücksichtigt, in dem sie zueinander stehen:

a. Im Methodischen gestattet die Ausführung keinen Ausgang von einem festen, höchsten Punkt und auch nicht einen unilinearen Gang auf einen solchen Punkt zu. Sie verlangt viele Wege von verschiedenen Punkten

\footnotetext{
${ }^{69}$ Eucken, Prolegomena, S. 18.

${ }^{70}$ Ebda., S. 17.

${ }^{71}$ Ebda., S.18.

${ }^{72}$ Eucken, Lebensanschauungen.
} 
aus und in mehreren Richtungen. Erforderlich ist also ein Methodenpluralismus, ein »Gefüge « von Methoden. ${ }^{73}$

Keiner der diesen Methoden folgenden Schritte ist unter Abstraktion von aller Erfahrung zu unterneh- $\{\mid$ S. 130 $\}$ men. Gelegentlich sprach Eucken sogar von einem »geistigen Positivismus «. ${ }^{74}$ Schon mit all dem verbietet sich für ihn eine Philosophie im Stil der von Fichte immer neu unternommenen Darstellungen der Wissenschaftslehre. Zu den verschiedenen Methoden gehören nicht nur »Analyse und Synthese in einer auf Erfahrung bezogenen Bedeutung, sondern beispielsweise auch »enge Verknüpfung der begrifflichen Forschung mit dem, was in weltgeschichtlicher Arbeit tatsächlich vorliegt«. Das entsprechende Vorgehen ist zwar mit der Überzeugung verbunden, »daß die That mehr enthalten mag als das Bewußtsein ${ }^{75}$ Eben deshalb aber wird ein »psychologisches Verfahren«, das von Erforschung des Bewusstseins ausgehen und geistige Vorgänge als Bewusstseinsbegebenheiten eines Subjekts behandeln würde, ${ }^{76}$ ausdrücklich abgelehnt. Es soll durch ein »noologisch« genanntes Verfahren ersetzt werden, in welchem sich die Frage, »was das Geistige am Einzelnen sei«, dahin umkehrt, »was der Einzelne am Geistesleben sei«. Dafür sind Ergebnisse des psychologischen Verfahrens allenfalls »Vorstufe der Erklärung «, nicht die Erklärung selbst. ${ }^{77}$ Es war daher verfehlt anzunehmen, Eucken wolle mit seiner noologischen Methode in Fichtescher Art vom sekundären Tatbestand des Bewusstseins zu einem »ursprünglichen Realleben « vordringen. ${ }^{78}$

$\{\mid$ S. 131\} b. Für die systematische Problembearbeitung, der die Methoden dienen sollen, ist eine ebenso inhaltliche wie epistemologische Vororientierung erforderlich, welche uns über die Geschichte der Weltanschauungen und Weltverhältnisse des Menschen aufklärt. Sie führt von der Antike bis an die Schwelle der Gegenwart und soll sowohl der Intention aufs systematisch-philosophische Erkennen als auch der kulturkritischen Funktion desselben allererst zu Erfolgs-Chancen verhelfen. Einer solchen historischen

73 Vgl. Eucken, Prolegomena, S. 41 ff.. Guten Aufschluss über den von Eucken programmierten Methodenpluralismus' gibt R. Falckenbergs ausführliche Rezension (1887) dieses Buchs in der Zeitschrift für Philosophie und philosophische Kritik S. 119-132.

74 - allerdings einem, »dem die Tat mit ihrer eigenen Wirklichkeit auch über die Wirklichkeit der Voraussetzungen und Bedingungen entschied « (vgl. Eucken, Lebenserinnerungen, S. 74).

${ }^{75}$ Eucken, Prolegomena, S. 97.

76 - und das »in dem, was an dem Einzelnen vorgeht und wie es in ihm vorgeht, ... den Gesamtbestand geistigen Daseins sieht « (ebda).

77 Eucken, Prolegomena, S. 98 f. In der Einheit des Geisteslebens heißt es, zur Erforschung der geistigen Wirklichkeit müsse, »wie wir es von Anfang an taten, vor die psychologische Methode eine noologische « gestellt werden (Ebd., S. 451).

78 - wie z. B. Fichte in der Bestimmung des Menschen vom ichzentrierten Zweifeln und gegenständlichen »Wissen« aus zum Aufweis einer »höchsten Synthesis« gelangen wollte, welche das Glauben an eine »intelligible Welt« rechtfertigen soll. So hat R. Falckenberg Euckens Absicht zunächst verstanden. Das Missverständnis dürfte erheblich dazu beigetragen haben, dass Eucken von anderen als Fichteaner wahrgenommen wurde. (Vgl. Falckenberg, ${ }^{1} 1886, \mathrm{~S}$ 465; ${ }^{6} 1908$, S. 590) Charakteristischerweise kommt Falckenberg bei seiner fichteanisierenden Deutung der Eucken'schen Forschungen von einem Überblick über die 1886 noch »neue Kantbewegung « her; und er vergleicht Euckens Forschungen, bevor er auf sie eingeht, mit der die Hegelische Ansicht vom objektiven Geist »gleichsam auf empirischem Weg « bestätigenden Völkerpsychologie von M. Lazarus und H. Steinthal. Eucken selbst aber hat sich seine Forschungsperspektive weder in Reaktion auf den Neukantianismus erarbeitet noch sie analog zur Abhängigkeit der Zeitschrift für Völkerpsychologie und Sprachwissenschaft vom vulgärhegelianisch verstandenen objektiven Geist gleichsam als empirische Bestätigung von Fichtes Bestimmung des Menschen und Hegels Grundlienien der Philosophie des Rechts entworfen. - Die erwähnte, ausführliche Besprechung von Euckens Prolegomena, die Falckenberg in der Zeitschrift für Philosophie und philosophische Kritik (Neue Folge Band 90. Halle 1887, S.110-142) seinem kurzen Euckenabschnitt von 1886 folgen lässt, kommt dann auch nur zu der viel vorsichtigeren Äußerung, ihr Verfasser habe sich bei der Beschäftigung mit Euckens Buch »öfter an die gleichfalls auf Einheit des Geisteslebens gerichtete Absicht und die tiefbohrenden Gedankengänge der Fichteschen Wissenschaftslehre erinnert« gefühlt. (Die Gefühle waren gewiss nicht angeregt von Euckens analytischem und synthetischem Verfahren.) Größer sei aber die Verwandtschaft mit Trendelenburg. - In Falckenbergs noch späterer, nurmehr kurzer Rezension von Die Einheit des Geisteslebens ... ist dann »mit Zuversicht « behauptet, dass Euckens Werk sich in einer Richtung bewegt, der die Zukunft gehört« (Neue Folge Band 96. Halle 1889. S. 306-311). Von einem Erinnert-werden an Fichte aber ist nicht mehr die Rede. 
Introduktion hatte sich Eucken in späten Basler Vorlesungen zugewandt und wird er 1890 (d. h. kurz nach Erscheinen des ersten systematischen Hauptwerks) Die Lebensanschauungen der großen Denker widmen, die auf Basler Vorlesungen basieren. Fichte ${ }^{79}$ erlangt darin keine erstrangige weltanschauungsgeschichtliche Bedeutung. Das bringt es mit sich, dass Euckens affirmatives Verhältnis zu philosophischen Gedanken Fichtes ziemlich pauschal bleiben kann und in den zentralen Punkten stets der gesamten Bewegung der nachkantischen Systemphilosophie gilt, der überdies samt ihrem Initiator Fichte für das nun verfolgte systematischphilosophische Programm Gegenwartsrelevanz nur mit Einschränkungen zugestanden wird. Entsprechend unscharf wird das Bild, das Eucken von $\{\mid$ S. 132\} Fichtes Philosophie entwirft. Deren Tat-Pathos aber findet Zustimmung aus ganz anderen als den in Fichtes Denken selbst gelegenen Gründen. ${ }^{80}$ So erklärt sich schließlich, weshalb an die »Selbsttätigkeit Fichtes« eigentlich nur erinnert wird, um das Ansichwahre und Ansichgute Platons »zu einer lebensvollen Wirklichkeit für uns zu machen«, sodass viele Behauptungen Euckens eher als an Fichte an Hegel gemahnen. Die ganze Bewegung, »die in Fichte mit richtender Kraft und feurigem Eifer einsetzt«, erreicht eben nach Euckens Auffassung erst »in Hegel ihre vollendende $\{\mid$ S. 133\} Höhe und reifste Durchbildung ${ }^{81}{ }^{81}$ Aber auch die ist nicht als solche bereits jene »Vertiefung und Erneuerung des Lebens «, deren es nun »zu unserer geistigen Selbsterhaltung « bedarf. ${ }^{82}$ Denn die Aufgabe der Philosophie ist jetzt weder die einer begreifenden Selbsterkenntnis der absoluten Idee noch diejenige einer Wissenschaftslehre und neuer, erst von ihr aus zu begründender spezieller philosophischer Disziplinen. Philosophie »darf nicht eine Sache der bloßen Gelehrsamkeit sein, auch nicht ein bloßes Gewebe von Reflexion und subjektivem Scharfsinn bleiben, sondern sie muß zu energischem Vordringen und geistigem Schaffen werden, sie muß Tiefen unseres Lebens herausarbeiten, schlummernde Kräfte beleben, vereinzelte Bestrebungen zusammenfassen, ja sie muß eine neue Wirklichkeit eröffnen, wenn sie für [...] Hauptfragen der Menschheit Hilfe leisten und zugleich die

79 - verglichen beispielsweise mit Platon, Aristoteles, Luther, Descartes, Spinoza, Leibniz, Kant, Goethe und Hegel. Einzig diese Personen werden in Euckens letztem systematischem Hauptwerk namentlich erwähnt (vgl. Mensch und Welt, S.454 ff.).

${ }^{80}$ Siehe vorne Fußnote 47! - Über »die alten Kantianer, wie Fichte, « wird in den Lebensanschauungen, S. 418) gesagt, wenn sie stürmisch über Kant hinausdrängten, seien sie »in besserem Recht gewesen als die neueren« der eigenen, inzwischen neukantianischen Gegenwart. Aber die nachfolgenden Ausführungen über Fichte als ersten in der Reihe nachkantischer Begründer von philosophischen Systemen fallen im Vergleich zur umfangreichen Besprechung Hegels fast spärlich aus. Am Ende befinden sie, Fichte sei »ein Mann weniger, aber großer Gedanken« gewesen, und auch bei diesen sei er »größer im Entwurf als in der Ausführung «. Gerühmt wird an ihm eigentlich nur sein »zugleich aufrüttelndes und befestigendes Schaffen, seine unbeugsame, zusammenhaltende, stählende, dabei stets den Tiefen des Lebens zugewandte Arbeit«. Mit ihr habe er »Unvergeßliches und Unverlierbares« gewirkt. Aber die Aufgabe, die er gefunden und - »an einen Wendepunkt des allgemeinen Lebens wie in eine kritische Zeit seines Volkes gestellt« - »mit hingebender Treue gelöst « habe, ist in Euckens Augen nur die »Weckung der Geister « gewesen (447). - In einem späteren Werk (Der Kampf um einen geistigen Lebensinhalt. Neue Grundlegung einer Weltanschauung. Leipzig 1895) urteilt Eucken eher noch zurückhaltender (mit Verweis auf Fichtes Bestimmung des Menschen): »Nicht weit können wir mit dem gewaltigen Stürmer gehen « $\left({ }^{2} 1907\right.$, S. 29). Lediglich Fichtes (von Eucken so bezeichneter) »Grundgedanke eines ursprünglichen und weltschaffenden Lebensprozesses im Menschen« findet »als das Fundament nicht nur aller Philosophie, sondern aller kräftigen Vernunftarbeit « emphatische Zustimmung, an die sich jedoch sogleich einschränkende Bemerkungen heften: 1. wider die Scheidung einer theoretischen und einer praktischen Vernunft und das Ausspielen der einen gegen die andere; 2. wider die subjektivistische Tendenz, die ganze Vernunft auf den Menschen zu stellen und zur Sache des bloßen Menschen zu machen; 3. wider die Behauptung, dass ein selbsttätiges Leben als Ursprung und Kern aller Geistigkeit »bei uns lediglich aus sich selbst allen Inhalt hervortreibe und unmittelbar unsere ganze Wirklichkeit schaffe«. Was Fichte zur Aufklärung der Möglichkeit genuin philosophischer, methodisch disziplinierter Erkenntnis und zur Erprobung solcher Möglichkeit geleistet haben mag, wird an keiner Stelle erwogen. - Auch Euckens sehr wohlwollende Rezension des Fichte-Buchs von Fritz Medicus (J. G. Fichte. Dreizehn Vorlesungen, gehalten an der Universität Halle. Berlin 1905) lässt keine Identifikation mit Fichtes Philosophie oder mit einem von deren Aspekten erkennen (Ein neues Buch über Fichte.). Charakteristischerweise distanziert sie sich sogar von Medicus' Konzentration auf die Wissenschaftslehre. Darüber trete anderes, wie insbesondere die Sittenlehre von 1798, zu sehr in den Hintergrund und werde der Einfluss Schellings auf den späteren Fichte unterschätzt.

${ }^{81}$ Eucken, Einführung in eine Philosophie des Geisteslebens, S.152.

${ }^{82}$ Ebd., S.158. 
Selbständigkeit ihrer eigenen Stellung wahren soll. Für solches vordringende Schaffen hat sie einen neuen und eigenen Standort zu suchen ... ${ }^{83}$ So kann sich nur äußern, wer in der Tat »selber oaner « sein will.

c. Ähnlich wie Hegels Phänomenologie als »ausführliche Geschichte der Bildung des Bewußtseins selbst zur Wissenschaft « ${ }^{84}$ sollen die Lebensanschauungen an die Schwelle gegenwärtiger, eigentlich systematischer Philosophie führen. Aber diese unterscheidet sich von idealistischer Systemphilosophie nicht nur im Methodischen. In inhaltlicher Hinsicht erlaubt sie nicht die ausschließliche Konzentration auf apriorische Grundlagen einer pragmatischen Geschichte des menschlichen Geistes in mir, dem Philosophierenden, dem die Fichte'sche Wissenschaftslehre solche Konzentration gebietet. Vielmehr verlangt sie die Aufmerksamkeit auf große, überindividuelle Kulturerscheinungen des menschlichen Arbeitslebens in der $\{\mid \mathrm{S}$. 134\} modernen Berufswelt einer industriellen Gesellschaft: Gegenwärtige Phänomene und Tatbestände, die sich tendenziell durch alle Lebensgebiete hindurchziehen und für die wir Namen von zeitspezifischen »-ismen« haben, wie »Naturalismus« und »Intellektualismus«. Eucken nennt sie häufig »Lebenssysteme«, macht aber darauf aufmerksam, dass mit »System« hier nicht ein Ganzes von Begriffen oder Dogmen gemeint ist, sondern ein jeweils Ganzes von »Lebensakten« mit ihren weit verzweigten Inhalten. ${ }^{85}$ Der Fachterminus, den er dafür einführt, lautet »Syntagma«, was im Griechischen wörtlich »Zusammengestelltes«, »Zusammengeordnetes« bedeutet, exemplarisch und in concreto aber vor allem »in Schlachtordnung aufgestellte Heerschar «. ${ }^{86}$ Wie in Schlachtordnung aufgestellte antike Heere Vieles organisierten und die Kräfte einer ganzen Population oder Polis bündelten, um diese sich in der Krise und im Kampf mit einer anderen behaupten zu lassen, — wie sie oftmals aber gerade dadurch die Lebensbedrohung aufs höchste steigerten, so stehen gegenwärtig miteinander rivalisierende Syntagmen in einem Kampf, bei dem es um viel Gewichtigeres geht als bloße »Ansichtssachen«, — um Bestände einer Weltanschauung, die man nicht gefahrlos gegeneinander austauschen kann, sobald die Umstände es nahelegen. Für die geistige menschliche Existenz kommt im Weltmaßstab alles darauf an, mithilfe einer Philosophie, welche die Struktur und Dynamik derart die eigene Gegenwart bestimmender Syntagmen offenlegt, den zwischen ihnen stattfindenden »Kampf um einen geistigen Lebensinhalt « für die ihn Bestreitenden humaner und durchsichtiger zu machen und so das der Philosophie Mögliche dazu beizutragen, dass der Kampf einen guten, sowohl der Freiheit als dem Glück der Menschen förderlichen Ausgang nimmt — in einem neuen Syntagma, das für eine weltgeschichtliche Epoche die berechtigten Forderungen der Syntagmen integriert, die zuvor einander die Alleinherrschaft streitig gemacht haben.

In dieser Perspektive untersucht Die Einheit des Geisteslebens den Naturalismus und den Intellektualismus und konzentriert sich an ihnen auf ihre polemisch gegeneinander gerichteten Zuspitzungen. Ihr erster Teil möchte beide Syntagmen deshalb nicht nur hinsichtlich ihrer grundsätzlichen Beschaffenheiten, sondern auch in ihren auf die Spitze getriebenen Formationen angemessen beschreiben. Er lässt keinen Zweifel daran, $\{\mid$ S. 135\} dass unter die »noetistisch« genannte Zuspitzung des Intellektualismus auch die gesamte nachkantisch-idealistische Systemphilosophie subsumiert wird. In einem zweiten, kritischen Teil des Werks wird aufzuweisen versucht, wie die beiden Syntagmen mit ihrem polemischen Verhältnis zueinander — einschließlich

${ }^{83}$ Ebd., S.193. Es sollte eigentlich schon deshalb keines Nachweises bedürfen, dass die Wahrnehmung dieser Aufgabe etwas anderes war als die ausschließlich religionsphilosophische von Fichtes Anweisung zum seligen Leben. Denn dies Leben ist nach Fichte stille Seligkeit, die im sich selbst gleichen Leben des Absoluten aufgeht, und ist von allem rastlosen, suchenden Tun befreit.

${ }^{84}$ Hegel, Phänomenologie des Geistes, S. 56.

${ }^{85}$ Eucken, Prolegomena, S. 74.

${ }^{86}$ - oder aber, als Ausdruck für ein abstractum, deren Ordnung, sowie dann auch »Staatseinrichtung «. 
der unter den noetistischen Intellektualismus subsumierten idealistischen Systemphilosophie — unter ihren eigenen Voraussetzungen sich selbst und nach eigenen Maßstäben beurteilt, unerbittlich zerstören, ${ }^{87}$ — es sei denn, beide werden überführt in ein sich ihnen entringendes, aber ihre berechtigten Motive integrierendes neues Lebenssystem. Eucken nennt es dasjenige der »Personalwelt«. In umrisshafter Darstellung, welcher der dritte Werkteil gewidmet ist, möchte er zeigen, dass dieses sich im Kampf der beiden anderen ankündigende neue Syntagma am Ende sogar den Gegensatz von Person und Sache überwinden wird.

Nun offenbart sich endlich die doppelt anti-Fichte'sche Pointe des Titels, den Eucken seinem Werk von 1888 gegeben hat. Sie besteht vor allem in der These, dass von der nachkantisch-idealistischen Systemphilosophie und ihrem »Noetismus« aus die Einheit des Geisteslebens gerade nicht in Bewußtsein und Tat der Menschheit zu erlangen ist; dass diese Einheit dafür vielmehr einen philosophischen Personalismus erfordert, wie er im »spekulativen Theismus« zu denken versucht wurde; zum anderen aber im Hinweis darauf, dass die Spätidealisten, wie z. B. Immanuel Hermann Fichte, dem sich abzeichnenden neuen Syntagma noch nicht wirklich Rechnung tragen konnten, weil sie $\mathrm{zu}$ sehr der alten metaphysischen Lehre von individueller, endlicher und unendlicher Seelensubstanz verhaftet blieben. ${ }^{88}$ — Worin das neue Lebenssystem der Personalwelt nach Euckens $\{\mid$ S. 136\} Auffassung des Näheren besteht und wie es die miteinander in Konflikt geratenen Inhalte des Naturalismus und Intellektualismus versöhnen soll, muss hier nicht mehr expliziert werden. Zur Wahrheitsfindung über einen angeblichen Neufichteanismus Euckens genügt es festzustellen, ob Gedanken, die in der Philosophie Johann Gottlieb Fichtes zentral und spezifisch waren, in Euckens Konzept einer Personalwelt Schlüsselbedeutung erlangt haben.

Das lässt sich von Fichtes Schriften bis 1799 guten Gewissens verneinen. Näher besehen gilt es aber auch nicht von denen des späteren Fichte ab 1800. Denn der Grundbegriff, von dem aus Eucken sein Syntagma der Personalwelt bestimmt und den er aus der Selbstkorrektur von Naturalismus und Intellektualismus gerechtfertigt glaubt, ${ }^{89}$ ist der eines universalen »kosmischen Selbstlebens «. Bereits er, dem man in seiner anfänglichen Unterbestimmtheit vielleicht eine Familienähnlichkeit mit dem Fichte'schen Begriff seligen Lebens in der Anweisung zusprechen möchte, unterscheidet sich, recht verstanden, hiervon signifikant. Denn er ist, obwohl Begriff wahrhaften Lebens, gerade nicht der eines Lebens im Einen, Absoluten oder in Gott und nicht Begriff

\footnotetext{
${ }^{87}$ Eucken, Die Einheit des Geistesleben, S. 250 f., vgl. 272 f., 277 f., 289 f., 293-295. - Trendelenburg hingegen wird anlässlich der 100. Wiederkehr seines Geburtstags (1902) zugut gehalten, er habe die Gefahr einer zu engen, einseitigen Gestaltung des Lebens erkannt, die in der nachkantisch-idealistischen Systemphilosophie bestand, und habe im Kampf dagegen eine führende Stellung eingenommen (Zur Erinnerung an Adolf Trendelenburg S. 113). Wie wäre mit diesem Urteil eine Neuorientierung der Philosophie an Fichte vereinbar gewesen? Nichts von einer solchen enthält auch Euckens 18 Jahre ältere Abhandlung über Trendelenburg: Zur Charakteristik der Philosophie Trendelenburgs.

${ }^{88}$ Exemplarisch dafür war Immanuel Hermann Fichtes Anthropologie (Leipzig 1856), deren weitere Bearbeitung bis zur Annäherung an den Spiritismus ging (vgl. Der neuere Spiritualismus, sein Wert und seine Täuschungen.) - Im Rückblick auf die 100. Wiederkehr des Geburtstages von Immanuel Hermann Fichte (1896), die »fast unbemerkt vorbeigegangen « war, hat Eucken am jüngeren Fichte nicht nur unter formalen Gesichtspunkten Intentionen gerühmt, in deren Fußstapfen er selbst getreten war: »ruhige und vermittelnde Arbeit«, die Wahrnehmung der Aufgabe, »den Widerstreit der Systeme, wie ihn die Geschichte der Philosophie äußerlich darbietet, [...] auszugleichen«, zugleich aber die »Spekulation mit ihrer Geschichte enger zu verbinden« und sich »um ein richtiges Verhältnis zwischen Spekulation und Erfahrung « zu bemühen. Er hat auch, näher aufs Inhaltliche eingehend, als erstes hervorgehoben, dass Immanuel Herman Fichtes Metaphysik durch eine charakteristische Grundansicht von Geistesleben beherrscht wird, die dessen Kern »nicht im Denken, überhaupt nicht in einer besonderen Leistung « findet, sondern ihn »in der Persönlichkeit, einem Beisichselbstsein und Sichselbstbehaupten des Geisteslebens sucht«. Dann aber hat Eucken, obwohl es sich um einen Nachruf handelte, seinen Lesern nicht vorenthalten, dass die nähere Ausführung des Grundgedankens eines solchen Kerns von Geistesleben den jüngeren Fichte »in schwierige Grenzgebiete voll problematischer Erscheinungen« führte, »denen gegenüber wohl ein kritischeres Verhalten angezeigt gewesen wäre« (Eucken, Zur Erinnerung an Immanuel Hermann Fichte, S.1-5).

${ }^{89}$ Vgl. Eucken, Die Einheit des Geisteslebens, S. 341.
} 
eines Lebens, dessen Element bloß der Gedanke ist, ${ }^{90}$ sondern ausdrücklich der kosmischen Lebens; und er $\{\mid \mathrm{S}$. 137\} wird uns auch nicht über jenen Fichte'schen Gedanken akosmischen seligen Lebens zugänglich. Wie im dritten Teil des Buches die weitere Erörterung und Ausdifferenzierung des Begriffs kosmischen Lebens zu dem einer Personalwelt sowie die versuchte Rechtfertigung der Behauptung einer solchen zeigen soll, ist der besagte Grundbegriff außerdem - anders als der Fichte'sche seligen Lebens - Bestimmung eines Lebens, das als solches durchgängig individuiert ist in vereinzelten endlichen Lebewesen.

Insofern könnte man versucht sein, solches Leben mit demjenigen in der von Fichte konzipierten intelligiblen Welt zu identifizieren, die ja eine freilich »überirdische« - Welt vieler, vereinzelter vernünftiger Wesen ist, - ein unsichtbares »Reich der Geister« mit einem in ihm allein herrschenden Gesetz und einem über das gegenwärtige irdische Leben hinausgehenden Zweck. Aber auch das wäre ein Missverständnis. Anders als das Leben in dieser intelligiblen Welt ist das »Personalleben« in der »Personalwelt« eines der irdischen Taten einzelner Menschen. Es ist ferner kein als »künftig« von meinem gegenwärtigen abgehobenes Leben, in das mich mein Wille schlechthin durch sich selbst einführt und in dem ich schon »unsterblich, unvergänglich, ewig« bin, sobald ich den Entschluss fasse, dem Vernunftgesetz zu gehorchen. Es ist auch kein Leben eines Gesetzes, das nach Fichte selbst schon »ein Wille« ist, ja sogar ein einziger, der »absolut durch sich selbst zugleich Tat ist und Produkt« und allererst mich mit sich selbst im »System von mehreren einzelnen Willen« verbindet. Vor allem aber ist Euckens »Personalleben « kein Leben in einem so intellektualweltlichen System, dass ich von ihm aus allererst durch hinzukommende $»$ sinnliche Anschauung ... zu einer persönlichen Intelligenz werde «, sodass ich mithin im System selbst, obwohl einzeln, durchaus noch nicht »persönliche Intelligenz« bin, sondern bloß Teil eines Lebens, als welches »alles unser Leben [...] Sein Leben ist «. ${ }^{91}$ Nicht einmal stützen möchte sich Eucken auf die Fichte'schen Aussagen über intelligible Welt. Vielmehr ist ganz unabhängig davon nach ihm das universale kosmische Selbstleben als »Personalleben« Leben einer Personalwelt und ihrer einzelnen Existenzen; und diese haben als so individuierte ein Prinzip der »Persönlichkeit« - als einer sich in »Wesenstaten« vollziehenden und in einer »Volltat« vollendenden »Gestaltung und Beherrschung der Mannigfaltigkeit aus Ei$\{\mid$ S. 138$\}$ nem Punkt « der »Lebenseinheit «. ${ }^{92}$ Das kosmische Selbstleben gibt ferner durch sein in ihm wirksames Persönlichkeitsprinzip dem Dasein durchgängig einen neuen Inhalt und stellt ihm neue Aufgaben. Sein »Personalsein« ist so jeweils »Träger einer Ordnung « und ist dies als »Realwesen«, in welchem der personale Träger nicht ohne Sache und nicht der Sache entgegengesetzt ist. Es ist ferner ein »Tatleben«, dies aber als »Weltwesen« einer »personalen Welt «.

Deren nähere begriffliche Bestimmungen — samt ihrer Verwendung in Behauptungen — sollen sich vom »Geistesleben der Menschheit« als der »höchsten Stufe der Wirklichkeit« aus durch ein angeblich kritisches Verfahren rechtfertigen lassen, ${ }^{93}$ das sich wie gesagt von demjenigen Fichtes grundlegend unterscheidet. Nicht zuletzt bildet unter den Schritten dieses Verfahrens und den Aspekten menschlichen Geisteslebens, auf die darin einzugehen ist, die ethische und die religiöse Welt nur einen Teil des Relevanten, wie ja auch nicht abstrakte Gedanken in einsamer Selbstreflexion untersucht und suggestiv aneinandergereiht werden sollen. An Facetten der geschichtlichen, empirisch zu erforschenden Wirklichkeit ist auszumachen, ob diese Wirklichkeit gemäß

\footnotetext{
${ }^{90}$ Vgl. dagegen Fichte, Anweisung zum seligen Leben. Erste Vorlesung.

${ }^{91} \mathrm{Vgl}$. Fichte, Die Bestimmung des Menschen.

${ }^{92}$ Eucken, Die Einheit des Geisteslebens, S.342.

${ }^{93}$ Ebd., S. 345-361.
} 
unserer Kenntnis von ihr im großen Maßstab eine Bewegung in die bezeichnete Richtung aufweist. ${ }^{94}$ Aus solcher Untersuchung soll sich ein »Gesamtbild des neuen Lebenssystems « ergeben, mit dem die Suche nach Einheit des Geisteslebens erfolgreich gefördert werden kann. ${ }^{95}$

Aus all dem erhellt wohl deutlich genug: Außer in methodischer Hinsicht kann die weitere Ausführung des Eucken'schen Programms auch inhaltlich nicht einmal der Fichte'schen Bestimmung des Menschen folgen. ${ }^{96}$ $\{\mid$ S. 139\} Fichtes intelligible Welt ist ja gerade keine Personalwelt einzelner Menschen mit einer jeweiligen, auch naturalen Individualität, sondern eine Welt bloß ihres intelligiblen, wenngleich vereinzelten Wesens, in dem alle gleich sind.$^{97}$ Es bleibt also dabei, dass Eucken der Philosophie Fichtes nicht mehr entnehmen kann als einen sich ins Lebensphilosophische wendenden Grundgedanken, der in sich selbst diese Wendung noch gar nicht enthielt und nur ohne sie Fichte eigen ist. Entsprechend selten und beiläufig fällt der Name »Fichte« in Euckens systematisch-philosophischen Schriften. Unabhängig davon kann man freilich Fichte und Eucken in vielerlei speziellen Hinsichten vergleichen und darlegen, inwiefern sich beide jeweils unterscheiden oder ähneln, und warum das so ist. Aber solche Vergleiche wären ohne Belang für die Beantwortung meiner Titelfrage, ob man es in Euckens Philosophie des Geisteslebens mit Neufichteanismus $\{\mid$ S. 140\} zu tun hat. Die Frage ist endgültig schlicht zu verneinen. Der angebliche Neufichteanismus Euckens war eine philosophiehistorische Legende.

\section{V}

Der vorhergehende Abschnitt (IV) hat hoffentlich aufgeklärt, was Eucken in seiner eigenen Perspektive mit Fichte verbindet und von ihm trennt. Wie aber nimmt sich der Zusammenhang zwischen beiden in der Sicht anderer aus — und über deren Wirkung auch noch in der unseren? Wie ist er abgesehen vom bei Eucken zu verneinenden Neufichteanismus positiv zu bestimmen? Gewiss ist mit dieser Verneinung nicht alles Nötige zu Eucken und Fichte gesagt, sondern stellen sich dazu nun neue Fragen. Einige von ihnen sollen am Ende

\footnotetext{
${ }^{94}$ Ebd., S. 361-389.

${ }^{95}$ Ebd., S. 390-481.

${ }^{96}$ Es wäre ein krasses Missverständnis, meiner Kontrastierung von Fichte und Eucken zu unterstellen, sie wolle diesen gegen jenen ausspielen und die Ausführung des Eucken'schen Programms, was Deutlichkeit und Überzeugungskraft betrifft, als Fichte überlegen behaupten. Schon R. Falckenberg fand Die Einheit des Geisteslebens [...] offenkundig enttäuschend und hat sie wohl auch deshalb nach seiner umfangreichen, respektvollen Besprechung der Prolegomena nur noch kurz rezensiert. Er vermisste »eine bestimmtere, schärfere, greifbarere Ausprägung des Grundgedankens«. Eucken sei »im Ablehnen entschiedener als im Behaupten« (ebd., S.310). Natorp aber hat keinen Zweifel daran gelassen, dass er die von Eucken versuchte Rechtfertigung der Behauptung eines universalen, kosmischen sowie personalen geistigen Selbstlebens nicht für überzeugend hielt und dass ihm der dafür zuletzt in Anspruch genommene »unmittelbare Beweis des Geistes und der Kraft« (ebd., S. 470) alles andere als schlüssig erschien. Er nennt das Konzept einer »Universal-Persönlichkeit« einen »metaphysischen Mythos « und macht darauf aufmerksam, dass Eucken den Beweis der Tatsächlichkeit einer solchen Persönlichkeit an der entscheidenden Stelle, an der es ihn gegen die stärksten Zweifel erfolgreich $\mathrm{zu}$ machen gälte, überraschenderweise schon durch Beschwichtigung viel schwächerer Zweifel geführt zu haben glaubt (ebd., S. 180, 183). Beide Einwände gegen die Ausführung, die Eucken seinem Programm 1888 gegeben hat, waren in meinen Augen voll berechtigt und wären leicht durch weitere zu ergänzen. Ähnlich entwaffnende Blößen hat sich Fichte nie gegeben. Aber das verstärkt nur die Gründe, die Unterschiede zwischen ihm und Eucken zu betonen.

${ }^{97}$ Infolge der langen Vorgeschichte, welche die von Eucken verhandelten »-ismen « und ihre Ergänzung durch eine neue Personalismus-Variante in philosophischen Weltanschauungen haben, gehen in ihre Beschreibungen auch Züge der von Trendelenburg begründeten Typenlehre grundlegend verschiedener Weltanschauungen ein, die in anderer Weise dann Dilthey, ebenfalls von Trendelenburg angeregt, weiterentwickelt hat. (Vgl. dazu Wach, 1926). In deskriptiver Hinsicht wird mit der Rekonstruktion solcher »-ismen« und »Syntagmen« etwas Ähnliches versucht, wie es wenig später Max Weber mit der Bildung von »Idealtypen« und mit deren Einsatz in der sozialwissenschaftlichen Erkenntnis unternahm, - nur dass philosophisch von der Einstellung des Rekonstruierenden zu ihnen nicht gefordert wird, sich mit ihr bei der weiteren Arbeit jeglicher wertenden Stellungnahme asketisch zu enthalten. Von einer Methodologie der Bildung und (noch viel schwierigeren) epistemischen Verwendung solcher Typusbegriffe blieb allerdings die gesamte Philosophie Euckens zu ihrem eigenen Schaden weit entfernt.
} 
identifiziert und wenigstens in gröbstem Umriss beantwortet werden.

(1) Wie ist die zählebige Legende vom Neufichteaner Eucken zu erklären? Das lässt sich nun leicht sehen. Die volle Anerkennung und Breitenwirkung, die Eucken fand, fiel just in die Jahre, in denen andere wie Heinrich Rickert und Hugo Münsterberg, die um 15 Jahre jünger waren als er, durch gezieltere Rückgriffe eine Fichte-Renaissance einleiteten und noch einmal 15 Jahre jüngere wie Lask und Medicus den Neufichteanismus begründeten. Weil aber der Ursprung von Euckens Philosophiekonzept unaufgehellt war und das Konzept zunächst nicht von Fichte-Experten identifiziert wurde, sind einige seiner untergeordneten Momente und Außenaspekte, denen zufolge für die Umsetzung eine Tatkraft wie die Fichtes gefordert wird, sowie entsprechende, besonders auffällige rhetorische Versatzstücke für die Hauptsache genommen und mit einer gerade stattfindenden, neuen Fichte-Rezeption kontaminiert worden. So adoptieren sich unreife Geisteskinder ihre Väter und werden fremd gewordenen Geistesheroen Vaterschaften angedichtet. ${ }^{98}\{\mid$ S. 141$\}$

Wirkliche Fachleute der Philosophie Fichtes wie Fritz Medicus sind, soweit ich weiß, darauf trotz großer Wertschätzung für Eucken nicht hereingefallen. ${ }^{99}$ Einer der ersten, der misstrauisch wurde, ohne jedoch die Rolle von Steffensen zu beachten, war der Erlanger Doktorand Paul Gabriel mit seiner Dissertation über Euckens Verhältnis zu Fichte. ${ }^{100}$ Gabriel hat wohl den Umschwung im Überweg zwischen 1906 und 1916 bewirkt, nicht aber im breiteren Publikum, zumal er gar nicht auf die Genese der Philosophie Euckens einging, sondern nur fertige Schriften beider Denker verglich. Wer außer versierten Philosophiehistorikern lässt sich unter solchen Umständen, wenn er sich seine Wahrnehmungsraster gebildet hat, von einem Doktoranden belehren?

(2) Welche Umstände aber haben das Aufkommen der Legende so begünstigt, dass ihm selbst ein vielbelesener und sorgfältig arbeitender Philosophiehistoriker wie Richard Falckenberg Vorschub leistete? Wie schon angedeutet spielte dafür eine erhebliche, allerdings irreführende Rolle, dass es für den Neukantianismus und die auf ihn Blickenden nahelag, den Weg von Kant zu Fichte, wenn auch vorsichtiger, zu wiederholen und dass Euckens systematische Philosophie in Erscheinung trat, als diejenige der ersten Neukantianer-Generation bereits kräftig zu wirken begonnen hatte. Zweifellos aber gab es unabhängig vom dadurch suggerierten Scheinzusammenhang auch im breiten Umfeld einer Verbindungslinie von Trendelenburg und Schleiermacher über Steffensen zu Eucken Ereignisse und Aspekte der Nachwirkung Fichtes, welche bei der Rezeption von Euckens sperriger Philosophie nahelegten, sich an den auctor der Nachwirkung zu $\{\mid$ S. 142\} erinnern. Wurden sie nicht für einen affirmativen Rückbezug von Eucken auf Fichte bedeutsam?

a. Unter solchen Ereignissen sind z. B. die zahlreichen akademischen Feiern zur 100. Wiederkehr von

98 Der Abstand zwischen dem Verhältnis Euckens zu Fichte und dem der rechtens als Neufichteaner zu bezeichnenden Autoren wird deutlich an zwei Büchern, die beide im selben Jahr erschienen sind: Münsterbergs Philosophie der Werte beginnt mit einem Fichte-Zitat (aus den Reden an die deutsche Nation) und läuft auf die Botschaft von Fichtes Anweisung zum seligen Leben zu, aus der dann am Ende zitiert wird (Münsterberg, 1908, S. 478). Rudolf Euckens Einführung in die Philosophie des Geisteslebens hingegen erwähnt Fichte bloß zweimal im Kontext einer sehr pauschalen Stellungnahme zur nachkantischen »konstruktiven Spekulation« (S. 146), die als Denken charakterisiert wird, das »unter energischer Abhebung vom bloß- menschlichen Befinden zu einem Weltprozesse « wachse und alles scheinbar Fremde sich zu eigenem Besitz gestalte. Als vermeintliche Lösung des Wahrheitsproblems aber habe dieses Denken seiner Einseitigkeit wegen bald Widerspruch finden müssen (S. 152 f.). Der Widerspruch wird auch nicht nur historisch registriert, sondern durch eigene Einwände verstärkt.

${ }^{99}$ Vgl. Medicus, 1927, S. 445-454.

${ }^{100}$ Gabriel, 1910. Die Dissertation wurde bei P. Kalweit auf Anregung von R. Falckenberg geschrieben. Sie indiziert also auch Zweifel, die Falckenberg inzwischen an seiner früheren Beurteilung des Verhältnisses von Eucken zu Fichte gekommen waren. 
Fichtes Geburtstag anno 1862. ${ }^{101}$ Die Feiern fielen in eine Zeit, in welcher sich die deutsche nationale Bewegung durch Vorgänge in der preußischen und österreichischen Politik neu belebte. Den Schwerpunkt dieses breitenwirksamen öffentlichen Gedenkens an Fichte bildeten die Reden an die deutsche Nation. Eucken jedoch, soweit ich sehe, nahm an diesen Feiern keinen erkennbaren Anteil. Zum Jahr 1908 allerdings, als die Reden 100 Jahre alt waren, hat der Insel-Verlag sie mit einem Vorwort von Eucken neu ediert. ${ }^{102}$ Wer das Vorwort las, ohne die Philosophie seines Verfassers zu kennen, mochte es als einen Aufruf verstehen, wenn schon nicht die Philosophie Fichtes, so zumindest dessen Ethos zu erneuern. Bei aufmerksamer Lektüre und wenigen EuckenKenntnissen hingegen war nicht zu übersehen, dass sich die Botschaft der Reden für den Herausgeber in einem erheblichen Abstand $\mathrm{zu}$ seiner eigenen Gegenwart und ihren Forderungen befand. ${ }^{103}$ Respektvoll und uneingeschränkt anerkannt hat Eucken an den politischen Schriften Fichtes zusätzlich zum vorbildlichen Ethos ihres Verfassers eigentlich nur, dass darin »zum ersten Mal die Idee der Nationalität mit voller Klarheit in die philosophische Betrachtung eintritt« und der Nationalgedanke an die höchsten Ziele des Menschen geknüpft wird. ${ }^{104}\{\mid$ S. 143$\}$

b. Neben der Rolle, welche der politische Redner Fichte seit Beginn der 60er Jahre erneut für die deutsche Nationalbewegung gewann, gab es um dieselbe Zeit im Bereich sittlicher und religiöser, aber unorthodoxer Gesinnungs- und Erbauungsliteratur vermutlich eine lebensweltliche und entsprechend diffuse Streuwirkung von Gedankensplittern aus Fichtes Populärschriften. Diese Wirkung war gegen Fragen des Philosophiekonzepts weitgehend indifferent und wurde gleichfalls durch das Jubiläumsjahr 1862 neu angefacht. Sie wurde aber wohl auch lebendig erhalten durch Immanuel Hermann Fichtes verehrungsvollen Umgang mit dem Oeuvre seines Vaters und vielleicht verstärkt durch eine für populäre Literatur typische Verwischung der Unterschiede, die zwischen beiden Denkern in ihren sittlichen und religiösen Überzeugungen bestanden. Eine sorgfältige mentalitätshistorische Recherche zu diesen verzweigten Literatur-Rinnsalen könnte darin vermutlich manch »herabgesunkenes« Fichte'sches »Kulturgut« entdecken. Im günstigsten Fall gäbe sie außerdem Aufschluss über Motive, die das Nachleben Fichtes und seines Sohnes später mit den Lebensreformbewegungen der Jahrhundertwende verbunden haben und sich dann auch im Soziotop des Eucken-Bundes tummelten. Vielleicht könnte das den Abgrund überbrücken helfen, der in unserem philosophiehistorischen Bewusstsein zwischen Fichtes unmittelbarer Wirkung und den Autoren des Neufichteanismus im Umkreis des Neukantianismus klafft. Zugleich würden dann wohl einzelne Fichte-ähnliche Aspekte an Euckens Philosophie des Geisteslebens weniger kontextarm erscheinen als in meinen obigen Ausführungen. Doch Anzeichen dafür, dass die Streuwirkung, welche Fichte'sche »Lichtfunken« in diesem Bildungs-Milieu hatten, für Euckens Denken genealogisch besonders relevant gewesen wären, kann ich nicht entdecken. Dass es über solche Nachwirkung Fichtes bei Eucken zur zentralen Bedeutung der pathetisch appelativen Rede von Tat, Volltat, Tatleben, Tatgeschehen gekommen ist, halte ich für sehr unwahrscheinlich. Auch die indirekte Wirkung, welche

\footnotetext{
${ }^{101}$ Vgl. hierzu Köhnke, 1983, S. 233-265.

102 Leipzig 1909.

103 Man vergleiche dazu den Anfang und Schluss des Vorworts! Moniert werden an den Reden ihre Darstellungsweise, ihr enger geschichtlicher Horizont, ihr schroffes Entweder-Oder, ihr Mangel an gelehrtem Wissen, ihre abwegigen Reformvorschläge; betont wird die längst vergangene Situation ihrer Veranlassung, die Andersartigkeit der gegenwärtigen Gefährdungen nationalen Lebens und die Unmöglichkeit, durch Anschluss an frühere Zeiten dem eigenen Handeln zu Hilfe zu kommen. So bleibt an den Reden eigentlich nur aktuell, dass sie ein »ergreifendes und erhebendes Schauspiel« bieten, uns Ziele vor Augen halten, uns mit Mut und Vertrauen erfüllen und unseren Glauben an die Kraft des Geistes sowie an die Tiefe unseres eigenen Wesens stärken. Potentiale zu neuen philosophischen Gedanken, die nun an der Zeit sind, werden von solchem Mut, Vertrauen und Glauben nicht automatisch mitgeliefert.

${ }^{104}$ Vgl. Eucken, Lebensanschauungen, S.446 f.
} 
authentische Gedanken des älteren Fichte über Schriften seines Sohnes gehabt haben, wird im Fall Euckens eher marginal gewesen sein.

(3) Sollte aber nicht die direkte Verbindungslinie von Schleiermacher über Steffensen zu Eucken mehr Rückbezug auf Fichte enthalten, als oben aufgedeckt wurde? Sicher nicht in der politischen Philosophie Fichtes und nicht in dessen Grundbegriff einer gedanklichen Tathandlung oder im Tatpathos philosophischer Kulturpredigt. Anders aber mag es sich mit $\{\mid$ S. 144\} dem Lebensbegriff und Programm einer Philosophie des Lebens verhalten. Im vielmaschigen Netz der Geschichte von Bestimmungen dieses Begriffs scheint es einige Gedankenfäden zu geben, die sich, von Fichte ausgehend, zu einer Philosophie des Geisteslebens verknoteten und durch Fortsetzungen solcher Verknotung schließlich zur Eucken'schen Lebensphilosophie führten. ${ }^{105}$ Ihre Erforschung hätte eine eingehende, begriffs- und diskursgeschichtliche Studie verdient. Sie müsste, glaube ich, von Fichtes Konzept einer transzendentalphilosophischen Wissenschaftslehre ausgehen und mit der $\mathrm{zu}$ ihm gehörigen Entgegensetzung philosophischer Spekulation gegen das wirkliche Leben beginnen. Die Entgegensetzung war ebenso schroff wie paradox formuliert. Leben ist ihr zufolge »ganz eigentlich NichtPhilosophieren«, während philosophische Spekulation »ganz eigentlich Nicht-Leben« sei, obwohl die Philosophie doch »für das unmittelbar Praktische pädagogisch in weitester Bedeutung dieses Wortes« sein soll und alles in ihr angeblich nicht etwas Ruhendes, Totes ist, sondern »Tat, Bewegung und Leben «. ${ }^{106}$ Fichte hat die Schroffheit dieser Entgegensetzung wenig später abgeschwächt. Vom in der Ichheit durch intellektuelle Anschauung aufzuweisenden Sein lehrte er 1804, es sei ein »esse in mero actu«, sodass beides, »Sein und Leben, und Leben und Sein durchaus sich durchdringen«; er sprach vom Einen und sich selbst gleichen »Leben der Vernunft«, das »in der irdischen Ansicht« sich spaltet in verschiedene Individuen und darum »im ganzen als Leben der Gattung erscheint«, aber auch »die Wurzel der Welt« ist; und schließlich erwog er sogar eine Wissenschaftslehre, »welche zugleich die einzig mögliche Lebenslehre ist «. ${ }^{107}$

Doch für Fichtes erste, frühromantische Rezipienten, die ihre Bildung und ihre Erwartungen an eine Philosophie fürs Leben aus vorkritischen Auffassungen von Lebensphilosophie bezogen hatten, ${ }^{108}$ war all das, soweit es ihnen noch bekannt wurde, nicht genug. Sie hielten ihre Distanz zur Fichte'schen Entgegensetzung von Philosophie und Leben auch nach Fichtes verbesserter Wissenschaftslehre und Explikation ihres Konzepts, die vor allem auf die Lehre vom seligen religiösen Leben zusteuert, ungemin- $\{\mid$ S. 145\} dert aufrecht. Der gelehrteste und wohl am frühesten in diesem zentralen Punkt gegen Fichte opponierende unter ihnen, der auch zweifellos am stärksten gewirkt hat, war der junge Schleiermacher. Kurz nach Veröffentlichung seiner Reden über die Religion schreibt er 1799 seine Monologen als einen Versuch, den philosophischen Standpunkt der Idealisten »ins Leben überzutragen«. Dazu will er in dieser Schrift den sittlichen und religiösen Charakter darstellen, der seiner eigenen Idee nach »dieser Philosophie entspricht «. ${ }^{109}$ Für den »philosophischen Standpunkt« steht ihm im Wesentlichen das spontan sich bestimmende Beisichselbstsein der Fichte'schen Transzendentalphilosophie. »Übergetragen« ins Leben aber, sodass Philosophie und Leben nicht voneinander getrennt bleiben, soll dieses Prinzip nicht mehr verlangen, dass die Philosophie sich in Gegensatz zum empirischen Leben bringt und ihr die Individualität des Philosophierenden, wie von Fichte gefordert,

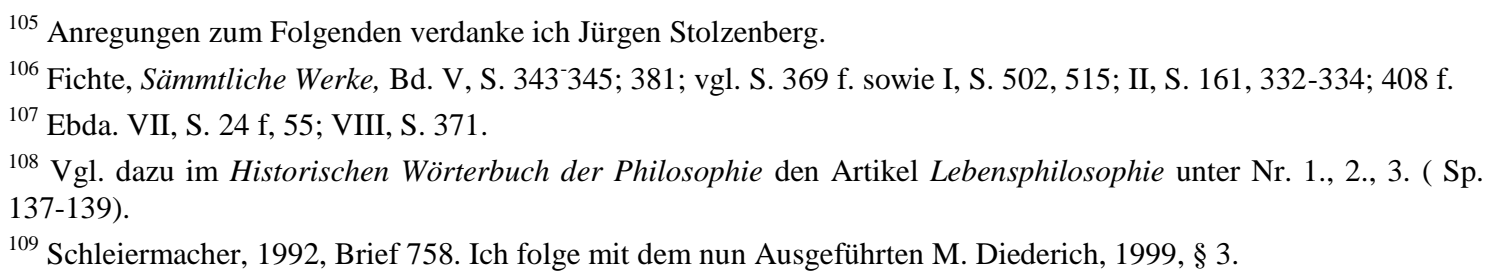


»unaufhörlich« absterbe. ${ }^{110}$ Vielmehr soll nun im konkreten Handeln menschlicher Individualität der Ort der Philosophie gefunden und diese dem Wesen des Menschen gerade in der Einheit von Denken und individuellem Handeln gerecht werden. Begrifflicher Ausgangspunkt und Interpretament hierfür ist darum auch nicht das Fichte'sche Ich bzw. die Ichheit in ihm, sondern der Geist in einer Auffassung seiner, die Schelling 1796/97 in den Abhandlungen zur Erläuterung des Idealismus Wissenschaftslehre skizziert hatte: der Geist als sich selbst anschauendes, mithin selbstbewusstes »absolutes Subjekt, für welches alles (auch er selbst) Objekt ist «. ${ }^{111}$ Aber das so verstandene Prinzip will von Schleiermacher wie gesagt sogleich in ethischer Rücksicht aufgenommen werden und nicht auf eine abstrakte Idealität des Menschen bezogen sein, sondern auf dessen empirische, individuelle Existenz — also auf das vereinzelte menschliche, wenngleich geistige Leben. — So ergab sich vom abstrakten Standpunkt der Fichte'schen Transzendentalphilosophie aus bei Schleiermacher eine ethische und religiöse Lebensphilosophie, die gleichwohl idealistisch blieb. ${ }^{112}$

In Auseinandersetzung mit ihrer Idee und in Distanzierung von ihren Idealisierungen dürfte Steffensen zu den oben umrissenen Überzeugun- $\{\mid$ S. 146\} gen gekommen sein, die dann zu entscheidenden Denkanstößen für Eucken geworden sind. Eucken hat dazu, wie es scheint, die Schleiermacher'sche Auseinandersetzung mit Fichte nicht erneut und in eigenständiger Weise aufgenommen, im Grundsätzlichen auch nicht die Steffensen'sche mit Schleiermacher. Aber er teilt mit Steffensen das distanzierte Verhältnis zu Schleiermacher und übernimmt das distanzierte Verhältnis Schleiermachers zu Fichte. Jedenfalls hat er an keiner Stelle seines eigenen Werks im Vergleich zu diesen zwischen ihm und Fichte stehenden Autoren eine Rückannäherung an Fichte zu erkennen gegeben. Die Barriere, auf diesem Überlieferungsweg zu Fichte zurückzugelangen, war für ihn ja sogar erhöht durch die Aufgabe, das individuierte Personsein zur Geltung zu bringen — und das in einer Situation, in welcher sich der Gegensatz zwischen Personalismus und antipersonalistischen, versachlichenden Tendenzen der eigenen Gegenwart erheblich verschärft hatte. So wird von Fichtes Gedanken im Zentrum des Begriffs geistigen Lebens nur das Charakteristikum ursprünglichen, spontanen und selbständigen Beisichselbstseins festgehalten. Einen stärkeren Überlieferungsfaden, der Fichte und Eucken in ihrer Philosophie miteinander verbindet, sich aber weniger bald als schon bei Schleiermacher zerfasert und in andere Gedankenstränge verliert, vermag ich nicht zu erkennen. Wenn es für Euckens Philosophie des Geisteslebens und seiner gegenwärtigen Syntagmen eine bedeutsame Wirkung Fichtes gegeben hat, war sie in der Hauptsache unterschwellig und doppelt indirekt. Sie erreichte Eucken vornehmlich durch das Nachleben von Schleiermacher in Steffensen und von Steffensen in ihm selbst

Lediglich mit seiner radikalen Abkehr von der Schleiermacherisch-idealistischen Christologie scheint Eucken erheblich über Steffensens Kritik an Schleiermacher hinausgegangen zu sein. ${ }^{113}$ Hingegen hat die Trendelenburg und Schleiermacher korrigierende, erneute Wertschätzung, die Eucken für Hegel entwickelte, ihn nicht dazu gebracht, die bei diesem zu findenden Potentiale begrifflicher Differenzierung im Reden von Leben überhaupt, naturalem Leben, geistigem Leben, Leben im Geist, lebendigem Geist und Leben des Geistes für seine eigene Philosophie des Geisteslebens fruchtbar zu machen. ${ }^{114}\{\mid$ S. 147$\}$

\footnotetext{
${ }^{110}$ Vgl. Fichte GA I, 4, S. 258.

${ }^{111}$ Schelling, Sämtliche Werke, Bd I, S. 367.

${ }^{112}$ Näheres hierzu Diederich, 1999, S. 37 ff.

${ }^{113}$ Vgl. dazu Eucken, Der Wahrheitsgehalt der Religion, S.423 ff.

114 Als Skizze zu diesen Potentialen vgl. meinen Aufsatz Das Leben des Geistes, S.27 ff. — Euckens Unbestimmtheiten hatten üble Folgen. Zum Beispiel ließ der Gedanke individuell-personalen geistigen Lebens für die Forderung einer Mitarbeit am Wirken überindividueller, objektiv-geistiger Mächte keine Chance, Handlungen, die
} 
Genau darauf wäre es angekommen, um die notorischen Vagheiten sowie Ambiguitäten Euckens zu überwinden und bessere Begründungen für dessen Behauptungen $\mathrm{zu}$ finden, also den Umgang damit hermeneutisch produktiv werden zu lassen. Es ist eine wichtige Devise, eine schwer zu fassende Philosophie durch Kontrastierung mit Verwandtem, das besser verstanden ist, zu erhellen. Doch wenn schon Euckens Philosophie des Geisteslebens auf diese Weise zugänglich gemacht werden sollte, so wäre sie weniger mit Fichte in Verbindung zu bringen als vor allem Hegel gegenüberzustellen gewesen. Sie dem Neufichteanismus zuzuschlagen, verbietet sich um doxographischer Objektivität willen. Aber der irisierende und irreführende Glanz, der vom dunklen Kapitel Fichte in Eucken ausging, verschwindet erst, wenn man entdeckt, dass es für unser eigenes philosophisches Interesse empfehlenswert ist, eine solche Zuordnung nicht einmal zu erwägen. Was möglicherweise an Euckens Geistphilosophie aktuell ist, besteht in anderem als den Themen und Fragen, mit denen uns Fichte bis heute zu beschäftigen hat.

\section{S. 148$\}$}

\section{Literaturverzeichnis}

Copleston, Frederick (1963), A History of Philosophy. Vol. VII, London/New York.

Cramer, Konrad (1996), Rudolf Christoph Eucken - Nobelpreisträger für Literatur - Philosoph. In: Göttinger Jahrbuch, Band 44, Göttingen, S. 230-232.

Dathe, U. (2000a), Rudolf Euckens Festrede zur Jahrhundertfeier. In: K.-M. Kodalle, hrsg., Angst vor der Moderne. Philosophische Antworten auf Krisenerfahrungen. Der Mikrokosmos Jena 1900 - 1940. Würzburg.

- (2000b), Rudolf Eucken - ein Gegner des Monismus und Freund des Monisten. In: P. Ziehe, hrsg., Monismus um 1900. Wissenschaftskultur und Weltanschauung. Berlin

Diederich, M. (1999), Schleiermachers Geistverständnis. Eine systematisch-theologische Untersuchung seiner philosophischen und theologischen Rede vom Geist. Göttingen.

Eucken, Rudolf (1866), De Aristotelis dicendi ratione. Pars I: Observationes de particularum usu. Diss. Gottingae. (Zitiert als De Aristotelis dicendi ratione).

- (1872), Die Methode der aristotelischen Forschung in ihrem Zusammenhang mit den philosophischen Grundprinzipien des Aristoteles. Berlin.

- (1881), Zur Erinnerung an K. Chr. Fr. Krause. Festrede, gehalten zu Eisenberg am 100. Geburtstage des Philosophen. Leipzig.

- (1884), Zur Charakteristik der Philosophie Trendelenburgs. In: Philosophische Monatshefte. Hrsg. v. C. Schaarschmid. Bd. XX. Heidelberg, S. 342-366.

- (1885), Prolegomena zu Forschungen über die Einheit des Geisteslebens in Bewußtsein und That der

Individuen jeweils möglich und in jeweiligen Rollen aufgegeben sind, sodass man zu ihnen sinnvoll auffordern kann, entschieden und deutlich, abzugrenzen von den Entscheidungs-Situationen im »Kampf um einen geistigen Lebensinhalt«, in denen individuelle Personen das geistige Leben menschlicher Kollektive oder der ganzen Menschheit durch Handlungen bereichern, ohne dass man sie dazu jemals mit philosophischen Worten auffordern könnte. 
Menschheit. Leipzig. (Zitiert als Prolegomena).

- (1888), Die Einheit des Geisteslebens in Bewußtsein und That der Menschheit. Leipzig. (Zitiert als Die Einheit des Geisteslebens).

- (1890), Die Lebensanschauungen der großen Denker. Eine Entwicklungsgeschichte des Lebensproblems der Menschheit von Plato bis zur Gegenwart. Leipzig. (Zitiert als Lebensanschauungen).

- (1894), Zur Philosophie der Geschichte von Karl Steffensen. Auszüge aus seinem handschriftlichen Nachlaß. Mit einem Vorwort von Prof. R. Eucken. Basel.

- $\quad\left({ }^{1} 1896\right)$, Der Kampf um einen geistigen Lebensinhalt. Neue Grundlegung einer Weltanschauung. Leipzig.

- (1899), Zur Erinnerung an Immanuel Hermann Fichte. In: Zeitschrift für Philosophie und philosophische Kritik. N.F. Bd. 110. Leipzig, S. 1-5.

- $\quad$ (21905), Der Wahrheitsgehalt der Religion. Leipzig.

- (1906a), Zur Erinnerung an Adolf Trendelenburg. In: Rudolf Eucken, Beiträge zur Einführung in die Geschichte der Philosophie. Leipzig.

- $\quad$ (1906b), Ein neues Buch über Fichte. In: Kant-Studien. Bd. 11 Berlin, S. 379-381.

— (1908), Einführung in eine Philosophie des Geisteslebens. Leipzig.

- (1915), Die Träger des deutschen Idealismus, Leipzig.

- (1918), Mensch und Welt. Eine Philosophie des Lebens, Leipzig. (Zitiert als Mensch und Welt).

- (1921), Lebenserinnerungen. Ein Stück deutschen Lebens, Leipzig. (Zitiert als Lebenserinnerungen). $\{\mid$ S. 149\}

Falckenberg, R. ( $\left.{ }^{1} 1886\right)$, Geschichte der neueren Philosophie von Nicolaus von Cues bis zur Gegenwart, Leipzig.

- (1887), Rezension von Rudolf Euckens Prolegomena zu Forschungen über die Einheit des Geisteslebens in Bewußtsein und That der Menschheit, In: Zeitschrift für Philosophie und philosophische Kritik (Neue Folge), Bd. 90, Halle, S.119-132.

Fichte, Immanuel Hermann (1856), Anthropologie, Leipzig.

- (1878), Der neuere Spiritualismus, sein Wert und seine Täuschungen. Leipzig.

Fichte, Johann Gottlieb (1834-1846), Sämmtliche Werke. Hrsg. v. I. H. Fichte, Berlin (Bd. V, I,II).

- (1910), Die Bestimmung des Menschen. In: Werke. Hrsg. v. Fritz Medicus, Bd. 3, Leipzig.

- $\quad$ (1910), Die Anweisung zum seligen Leben oder auch die Religionslehre. In: Werke. Hrsg. v. Fritz Medicus, Bd. 5, Leipzig.

— (1969), über den Begriff der Wissenschaftslehre 1794. In: Johann Gottlieb Fichte-Gesamtausgabe. Hrsg. v. d. Bayerischen Akademie der Wissenschaften. Bd. 1,2: Hrsg. v. Reinhard Lauth. Stuttgart/Bad Cannstatt, S.93-499. (Zitiert als GA mit Angabe des Bandes, der Abteilung und der Seitenzahl).

Fulda, Hans Friedrich (2006), Das Leben des Geistes. In: Hegel-Jahrbuch 2006. Berlin, S. 27-35

Gabriel, Paul (1910), Euckens Grundlinien einer neuen Lebensanschauung und sein Verhältnis zu Johann Gottlieb Fichte. Bunzlau. 
Gillispie, Ch. C. (Hg.) (1970), Dictionary of Scientific Biography. Vol III., New York.

Gunkel, Hermann (Hg.) (1930), Religion in Geschichte und Gegenwart. Handwörterbuch für Theologie und Religionswissenschaft, darin: Artikel über Eucken, Bd. IV, Tübingen, S. 498f. (Zitiert als RGG).

Hartmann, E v. (1869 ff.), Philosophie des Unbewussten, Berlin.

Hegel, Georg Wilhelm Friedrich (1980), Phänomenologie des Geistes, In: G. W. F. Hegel, Gesammelte Werke, Band IX, Hamburg.

Hoeres, P. (2004), Der Krieg der Philosophen. Die deutsche und die britische Philosophie im Ersten Weltkrieg. Paderborn.

Husserl, Edmund (1927), Die Phänomenologie und Rudolf Eucken, in: Die Tatwelt. Zeitschrift für Erneuerung des Geisteslebens. Jahrgang III, Heft 1/3. Jena, S. 10-11

Jahn, Bruno (2001), Biographische Enzyklopädie deutschsprachiger Philosophen. München.

Klose, O. und Rudolph, E. (Hg.) (1974), Schleswig-Holsteinisches Biographisches Lexikon, Neumünster, S. 254-258.

Köhnke, K. Chr. (1983), Philosophische Begriffe in wissenschaftsinterner und -externer Kommunikation. Am Beispiel der Fichte-Festreden des Jahres 1862. In: Archiv für Begriffsgeschichte. Bd. 27, S.233-265.

Lersch, Philipp (1932), Lebensphilosophie der Gegenwart, in: Philosophische Forschungsberichte. Heft 14. Berlin.

Liebmann, Otto (1865), Kant und die Epigonen. Eine kritische Abhandlung. Stuttgart.

Medicus, Fritz (1905), J. G. Fichte. Dreizehn Vorlesungen, gehalten an der Universität Halle. Berlin. $\{\mid$ S. 150\} - $\quad$ (1927), Rudolf Eucken zum Gedächtnis. In: Kant-Studien. Bd. XXXI (1927). S. 445-454

Münsterberg, Hugo (1908), Philosophie der Werte. Leipzig.

Natorp, Paul (1892), Rezension zu Rudolf Euckens Die Einheit des Geisteslebens, in: Philosophische Monatshefte (hrsg. v. P. Natorp), Bd. 28, Berlin, S. 154-185.

Nietzsche, Friedrich (1986), Sämtliche Briefe. Kritische Studienausgabe. Bd. III. München.

Pesch, R. (1982), Die politische Philosophie Fichtes und ihre Rezeption im Nationalsozialismus. Kassel (Marburger Dissertation 1983).

Ritter, Joachim (Hg.) (1980), Artikel: Lebensphilosophie, in: Joachim Ritter (Hg.): Historisches Wörterbuch der Philosophie, Bd. V, Basel/Darmstadt, Sp. 135-140.

Scheler, Max (1973), Deutsche Philosophie der Gegenwart. In: Max Scheler, Gesammelte Werke. Bd. VII. Bern. Schelling, F.W. (1856-1861), Sämtliche Werke, hrsg. v. K.F.A. Schelling. Bd. I, Stuttgart.

Schleiermacher, Fr. D. E. (1992), Brief an C.G. v. Brinckmann vom 23. 12. 1799 bis 4. 1.1800. In: Fr. D. E. Schleiermacher, Kritische Gesamtausgabe, hrsg, v. H.-J. Birkner u.a., Abt. V, Bd 3. Berlin, Brief 758.

Steffensen, Karl. Gesammelte Vorträge und Aufsätze mit einigen Erinnerungsblättern von Freunden und Schülern. Ohne Herausgeber. Basel 1890.

Stuke, H. (1963), Philosophie der Tat. Studien zur Verwirklichung der Philosophie bei den Junghegelianern und den wahren Sozialisten, Stuttgart.

Totok, Wilhelm (1986), Handbuch der Geschichte der Philosophie, Bd. 5, Frankfurt a. M. (Bd. 6,1990). 
Trendelenburg, Adolf (1862), Zur Erinnerung an Johann Gottlieb Fichte. Vortrag, gehalten in der Königl. Friedrich-Wilhelms-Universität zu Berlin am 19. Mai 1862. Berlin.

Ueberweg, Friedrich $\left({ }^{9} 1902\right)$, Grundriß der Geschichte der Philosophie, hrsg. v. M. Heinze. Bd. IV. Berlin.

Wach, J. (1926), Die Typenlehre Trendelenburgs und ihr Einfluß auf Dilthey. Eine philosophie- und geistesgeschichtliche Studie. Tübingen.

Windelband, Wilhelm ( $\left.{ }^{4} 1907\right)$, Lehrbuch der Geschichte der Philosophie. Tübingen.

Wuchterl, Kurt (1995), Bausteine einer Geschichte der Philosophie des 20. Jahrhunderts. Bern. 